ETS-RT - 2002-002

\title{
HIERARCHICAL CONTROL OF PRODUCTION AND MAINTENANCE RATES IN MANUFACTURING \\ SYSTEMS
}

JEAN-PIERRE KENNE EL-KÉBIR BOUKAS 
ETS-RT - 2002-002

\title{
HIERARCHICAL CONTROL OF PRODUCTION AND MAINTENANCE RATES IN MANUFACTURING SYSTEMS
}

\section{TECHNICAL REPORT}

\author{
JEAN-PIERRE KENNE \\ Département de génie mécanique \\ EL-KÉBIR BOUKAS \\ École Polytechnique, Département de génie mécanique
ÉCOLE DE TECHNOLOGIE SUPERIEURE
UNIVERSITE DU QUEBEC

MONTRÉAL, OCTOBER 9, 2002 
ETS-RT - 2002-002

\section{HIERARCHICAL CONTROL OF PRODUCTION AND MAINTENANCE RATES IN MANUFACTURING SYSTEMS}

JEAN-PIERRE KENNE

Département de génie mécanique

ÉCOLE DE TECHNOLOGIE SUPERIEURE

EL-KÉBIR BOUKAS

Département de génie mécanique

ÉCOLE POLYTECHNIQUE

Electronic version of this technical report is available on the École de technologie supérieure web site (http://www.etsmtl.ca).

In order to request a paper copy, please contact :

Service de la bibliothèque

École de technologie supérieure

1100, rue Notre-Dame Ouest

Montréal (Québec)

$\mathrm{H} 3 \mathrm{C} 1 \mathrm{~K} 3$

Phone : (514) 396-8946

Fax : (514) 396-8633

Email : biblio@etsmtl.ca

C École de technologie supérieure 2002

The quoting of excerpts or the reproduction of short sections of this report are permitted only if the name of the author and reference to the document are given. Reproduction of all quantitatively or qualitatively important sections of the report requires authorization of the owner of the copyright.

ISBN 2-921145-37-5

Legal Deposit : Bibliothèque nationale du Québec, 2002

Legal Deposit : National Library of Canada, 2002 


\title{
APPROCHE HIERARCHISEE APPLIQUEE AU CONTROLE DES TAUX DE PRODUCTION ET DE MAINTENANCE DES SYSTEMES MANUFACTURIERS
}

\author{
JEAN-PIERRE KENNE \\ EL-KÉBIR BOUKAS
}

\section{SOMMAIRE}

Les systèmes de production sont en général constitués de plusieurs machines interconnectées qui produisent simultanément plusieurs types de pièces. Ces machines sont sujettes à des pannes et réparations aléatoires. La dynamique des pannes de ces machines dépend de leurs âges et leur disponibilité dépend des stratégies de maintenance adoptées. Dans ce contexte, le problème de planification de la production et de la maintenance de ces types de systèmes de production peut être formulé comme un problème d'optimisation stochastique de grande dimension. Cette dimension croît de façon exponentielle avec le nombre de machines et de types de pièces considérées. Les problèmes d'optimisation stochastique associés à une telle dimension sont complexes et très difficiles à résoudre de nos jours.

L'objectif de cette recherche est de déterminer une loi de commande sous optimale, constituée des taux de production et de maintenance, qui approxime la loi de commande de ces problèmes complexes. Pour formuler le problème d'optimisation à résoudre, nous proposons une approche de commande hiérarchisée à deux niveaux. Cette approche consiste à utiliser les méthodes des perturbations singulières pour transformer le problème de commande stochastique initial en un problème de commande déterministe équivalent. L'approche de Kushner est par la suite appliquée au problème déterministe pour obtenir un problème de décision markovien. En résolvant ce problème de faible dimension à l'aide des méthodes numériques, nous obtenons une loi de commande à partir de laquelle nous construisons la loi de commande recherchée pour le problème d'optimisation stochastique initial. Une méthode heuristique est proposée pour une telle construction. Des modèles de simulation sont enfin utilisés pour valider l'approche de 
commande proposée dans cette recherche. Les résultats de la recherche sont appliqués sur un exemple de système de production constitué de deux machines produisant deux types de pièces. 


\title{
HIERARCHICAL CONTROL OF PRODUCTION AND MAINTENANCE RATES IN MANUFACTURING SYSTEMS
}

\author{
JEAN-PIERRE KENNE \\ EL-KÉBIR BOUKAS
}

\begin{abstract}
This paper deals with the production and preventive maintenance planning control problem for a multi-machine flexible manufacturing system (FMS). A two-level hierarchical control model is developed according to the discrepancy between the time scale of the discounting cost event and the one of the machines states process. The proposed model extends the classical singular perturbation approach by considering age dependent machines failure rates and controlling both production and preventive maintenance rates. We replace the stochastic optimal control problem by a deterministic control problem called limiting control problem. With this approach, we compute an age dependent near-optimal control policy of the stochastic initial control problem from the optimal solution of the equivalent limiting control problem. A numerical example is used to illustrate the procedure and to show the reduction of the control problem size.
\end{abstract}

Key words : Production Control, Preventive Maintenance, Hierarchical Control, Singular Perturbations, Flexible Manufacturing Systems. 
TABLE OF CONTENTS

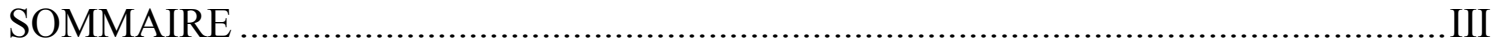

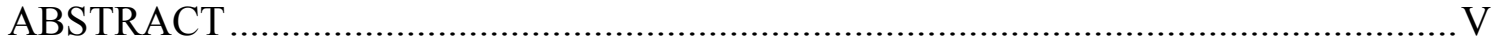

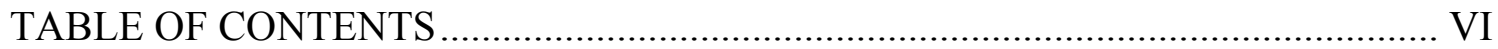

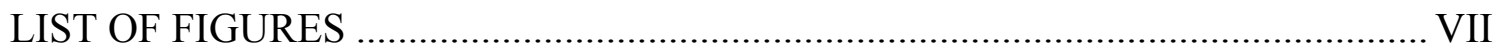

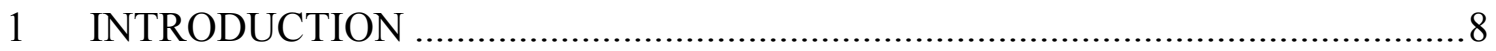

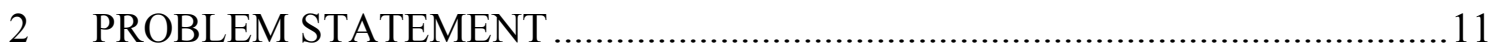

3 PROPRETIES OF THE VALUE FUNCTION ………………........................... 16

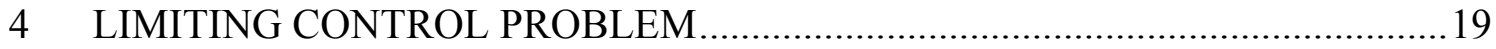

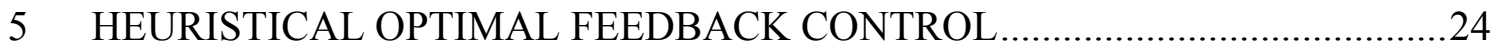

6 EXPERIMENTATION OF THE PROPOSED APPROACH ………………….....28

7 CONCLUSION

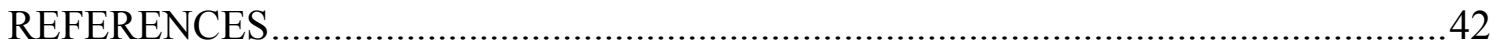




\section{LIST OF FIGURES}

Figure 1. Hierarchical control approach................................................................... 13

Figure 2. Classes of operational machines ................................................................. 26

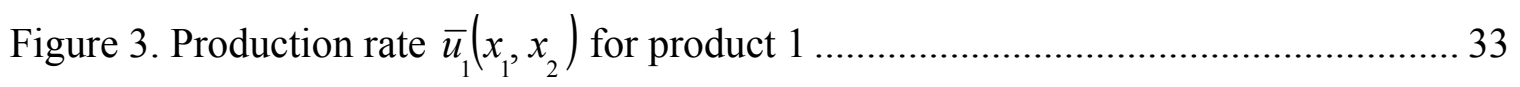

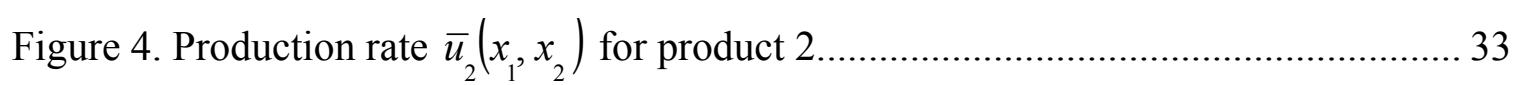

Figure 5. Preventive maintenance rate $\bar{\omega}_{2}\left(x_{1}, x_{2}\right)$ for the limiting problem .................... 34

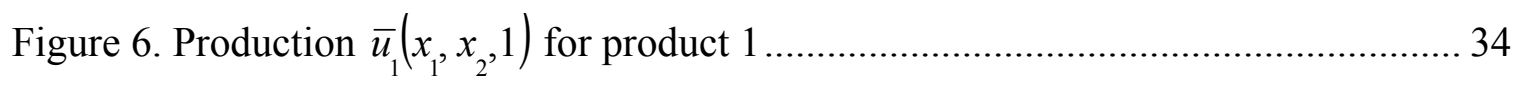

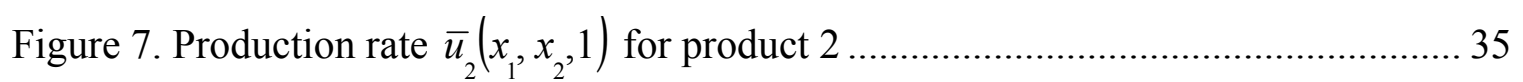

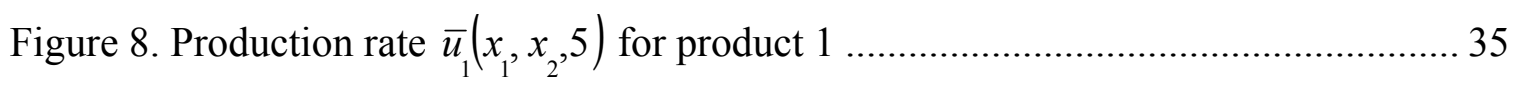

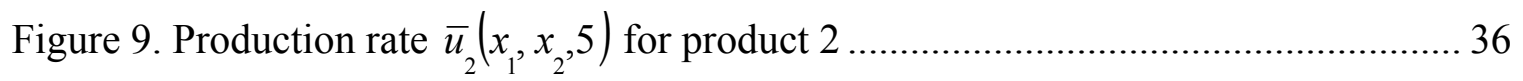

Figure 10. Preventive maintenance rate $\bar{\omega}\left(x_{1}, x_{2}, 1\right)$ for the limiting problem .................. 36

Figure 11. Preventive maintenance rate $\bar{\omega}\left(x_{1}, x_{2}, 5\right)$ for the limiting problem.................. 37

Figure 12. Machines production rates at mode 1 for $a_{1}=1$ and $a_{2}=3$ (product 1)........ 37

Figure 13. Machines production rates at mode 1 for $a_{1}=1$ and $a_{2}=3$ (product 2)....... 38

Figure 14. Machines production rates at mode 1 for $a_{1}=3$ and $a_{2}=5$ (product 1 ) ...... 38

Figure 15. Machines production rates at mode 1 for $a_{1}=3$ and $a_{2}=5$ (product 2) ....... 39

Figure 16. Machines preventive maintenance rates at mode 1 for $a_{1}=1$ and $a_{2}=3 \ldots . .39$

Figure 17. Machines preventive maintenance rates at mode 1 for $a_{1}=3$ and $a_{2}=5 \ldots .40$ 


\section{INTRODUCTION}

Today's manufacturing systems have more sophisticated and dynamic nature than the ones in the past. Most of them are large dynamic systems characterized by several machines and a large number of different products. Moreover, such systems are subject to discrete events such as machine failures and repairs, demand fluctuations, etc. Thus, in many instances, manufacturing systems are unreliable systems. Over time, their dynamics moves from one mode to another according to various kinds of discrete events. The control policies of such systems must be able to react to these events and to minimize a given criteria index. The related control problem is and extremely complex one. This complexity is mainly due to the unreliability of the systems and the large number of machines and products involved.

The problem of controlling manufacturing systems with unreliable machines was formulated as a stochastic control problem by Older and Suri (1980). The failures and repairs processes were supposed to be described by homogeneous Markov processes. The related optimal control model fails in the category of problems studied previously by Rishel (1975). Investigation in the same direction gives rise to the analytical solution of the one-machine one-product manufacturing system obtained by Akella and Kumar (1986). In the case of non-homogeneous Matkov processes, the control problem becomes more complex. In this sphere, Boukas and Haurie (1990) considered the fact that the failure probabilities of a machine depend on its age and they added to the existing models the possibility to do preventive maintenance. The related age dependent set of dynamic programming equations were solved numerically for the two-machine one-product manufacturing system. However, with the numerical scheme presented by Boukas and Haurie (1990), it remains difficult to obtain the optimal control of a large scale FMS (more than two machines). The only way to cope with such a difficulty is to develop heuristical methods based on the reduction of the size of the considered control problem. Hence, different approaches have been proposed in the literature in order to derive simple near-optimal control policies in manufacturing. 
The concept of hedging point policy, introduced by Kimemia and Gershwin (1983), is one of the simple ways of finding suboptimal control policies in manufacturing. For further details on this concept, we refer the reader to the age dependent hedging point concept presented by Boukas et al. (1995b), Kenne et al. (1997) and Kenne and Gharbi (2000). For large scale FMS, the derivation of suboptimal policies based on this concept seems to be difficult due to the computation of the threshold levels.

Another approach is to develop hierarchical control methods based on the particular structure of the system. This can be done by using the singular perturbation approach. The main idea of this approach is to simplify the complexity of a large system control problem according to the discrepancy between the time scales of different events. By replacing fast processes by their mean values, one can construct a deterministic limiting problem, which is computationally more tractable. Details on this approach can be found in Lehoczky et al. (1991), Sethi and Zhang (1994b) and Soner (1993).

In this paper, we will extend the production rate control model presented in Lehoczky et al. (1991), Soner (1993) and Sethi et Zhang (1994a) to the case where the capacity of the system is age dependent and some jump rates are influenced by the control policy. The production and maintenance rates of the FMS will be derived from the numerical solution of the equivalent limiting problem. The purpose of the paper is to show how some large-scale stochastic control problems involving different time scale processes can be approximated in such a way that they become numerically tractable. Our main contribution is the derivation of a FMS age dependent control policies using the singular perturbation approach. We will illustrate our approach on a numerical example, which consists of two machines producing two part types.

The paper is organized as follows. In section 2, we present the problem formulation of the production and maintenance rates control of a FMS subject to different time scale processes. Section 3 is devoted to the related optimal control problem. We develop the 
limiting control problem and the construction of the suboptimal solution of the original problem in section 4 . The proposed numerical algorithm is presented in section 5 . In the last section, we apply the proposed method to a numerical example to illustrate the effectiveness of the method. 


\section{PROBLEM STATEMENT}

In this section, we present an explicit singular perturbation form of the control model for a multiple identical machines system. Thus, a hierarchical approach for solving the control problem of the FMS is the main frame of the proposed formulation. The system under study consists of $m$ identical machines producing $n$ different part types. The operational mode of the machine $i$ can be described by a stochastic process $\zeta_{\mathrm{i}}(\mathrm{t})$ $(1 \leq \mathrm{i} \leq \mathrm{m})$. such a machine is available when it is operational $\left(\zeta_{\mathrm{i}}(\mathrm{t})=1\right)$ and unavailable when it is under repair $\left(\zeta_{\mathrm{i}}(\mathrm{t})=2\right)$ or under preventive maintenance $\left(\zeta_{\mathrm{i}}(\mathrm{t})=3\right)$. We then have $\zeta_{\mathrm{i}}(\mathrm{t}) \in \mathrm{B}_{\mathrm{i}}=\{1,2,3\}$. We can describe the operational mode of the FMS by the random vector $\zeta(\mathrm{t})=\left(\zeta_{1}(\mathrm{t}), \cdots, \zeta_{\mathrm{m}}(\mathrm{t})\right)$ with values in $\mathrm{B}=\mathrm{B}_{1} \times \cdots \times \mathrm{B}_{\mathrm{m}}$.

Let $\mathrm{a}=\left(\mathrm{a}_{1}, \cdots, \mathrm{a}_{\mathrm{m}}\right)^{\prime}$ and $\omega=\left(\omega_{1}, \cdots, \omega_{\mathrm{m}}\right)^{\prime}$ denote the vector of machines ages and the vector of preventive maintenance rates respectively. The process $\zeta(\mathrm{t})$ is modelled by a continuous time Markov chain defined by machines ages and control dependent transition rates matrix $\mathrm{Q}(\mathrm{a}, \omega)=\left[\lambda_{\alpha \beta}(\mathrm{a}, \omega)\right]$ with $\sum_{\beta=1}^{\mathrm{M}} \lambda_{\alpha \beta}(\mathrm{a}, \omega)=0, \alpha=1, \cdots, \mathrm{M}$, with $\mathrm{M}=\operatorname{card}(\mathrm{B})$. The transition rates $\lambda_{\alpha \beta}($.$) are derived from the combination of those of$ the dependent processes $\zeta_{\mathrm{i}}(\mathrm{t}), \mathrm{i}=1, \cdots, \mathrm{m}$. One can describe $\zeta_{\mathrm{i}}(\mathrm{t})$ statistically by the following state probabilities:

$$
\mathrm{P}\left[\zeta_{\mathrm{i}}(\mathrm{t}+\delta \mathrm{t})=\beta \mid \zeta_{\mathrm{i}}(\mathrm{t})=\alpha\right]=\left\{\begin{array}{cc}
\lambda_{\alpha \beta}^{\mathrm{i}}(.) \delta \mathrm{t}+\mathrm{o}(\delta \mathrm{t}) & \text { if } \alpha \neq \beta \\
1+\lambda_{\alpha \beta}^{\mathrm{i}}(.) \delta \mathrm{t}+\mathrm{o}(\delta \mathrm{t}) & \text { if } \alpha=\beta
\end{array}\right.
$$

where

$$
\lambda_{\alpha \beta}^{\mathrm{i}}(.) \geq 0 \quad \lambda_{\alpha \alpha}^{\mathrm{i}}(.)=-\sum_{\beta \neq \alpha} \lambda_{\beta \alpha}^{\mathrm{i}}(.) \quad\left(\alpha, \beta \in \mathrm{B}_{\mathrm{i}}\right) \text { and } \lim _{\delta \mathrm{t} \rightarrow 0} \frac{\mathrm{o}(\delta \mathrm{t})}{\delta \mathrm{t}}=0
$$


For the example of two machines, the set of possible values of $\zeta(\mathrm{t})$ can be determined from the values of $\zeta_{1}(t)$ and $\zeta_{2}(t)$ as illustrated in table I.

Table I. Modes of a two-machine manufacturing system

\begin{tabular}{|l|l|l|l|l|l|l|l|l|l|}
\hline$\zeta_{1}(\mathrm{t})$ & 1 & 1 & 1 & 2 & 2 & 2 & 3 & 3 & 3 \\
\hline$\zeta_{2}(\mathrm{t})$ & 1 & 2 & 3 & 1 & 2 & 3 & 1 & 2 & 3 \\
\hline$\zeta(\mathrm{t})$ & 1 & 2 & 3 & 4 & 5 & 6 & 7 & 8 & 9 \\
\hline
\end{tabular}

Our approach is used when the rate of change in the machine states is much larger than the rate at which the cost is discounted. In this paper, we assume a constant demand rate without any loose of generality. Two time scales are then considered: the discounting cost event and the machines states process time scales. When the difference between the two time scales is very large, one can split the time. Thus, the transition rates for the system, $\lambda_{\alpha \beta}($.$) , can be expressed as \varepsilon^{-1} \mathrm{q}_{\alpha \beta}($.$) where \mathrm{q}_{\alpha \beta}($.$) and the discount rate have the$ same magnitude. We can describe the behaviour of the system by a process $\zeta^{\varepsilon}(t)$ associated to the infinitesimal generator $\mathrm{Q}^{\varepsilon}($.$) defined as follows:$

$$
\mathrm{Q}^{\varepsilon}(.)=\frac{1}{\varepsilon}\left[\mathrm{q}_{\alpha \beta}(.)\right] \quad \alpha, \beta \in \mathrm{B}
$$

The singular perturbation parameter $\varepsilon$ is used here to express the hierarchical structure of the proposed approach. With $\varepsilon<<1$, one can derive, from the formulation of the initial stochastic problem, an equivalent deterministic problem. The related control approach is illustrated in figure 1. Both control problems (stochastic and deterministic) are described by dynamic programming equations (DPE) presented in sections 3 and 4 . The significance of the structure depicted in figure 1, for the decision-making hierarchy, is that the planning level management can ignore the day-to-day fluctuations in machines capacities, or generally, the details of shop floor events. This is given by the 
limiting problem formulated at 1 . The operational level management can then derive approximate optimal policies for running the actual (stochastic) manufacturing system. We will provide the control for this level, namely level 2 of the proposed hierarchy, by construction a near-optimal control policy from the one of the limiting problem (level 1).

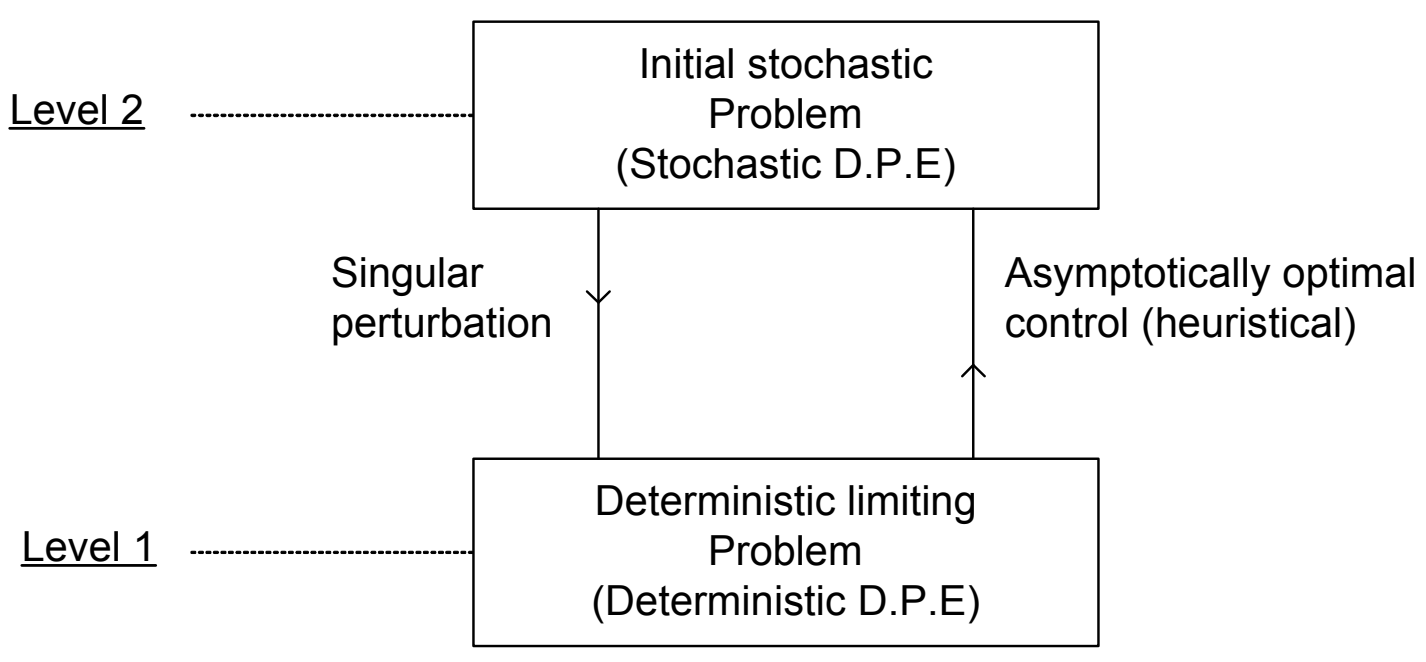

Figure 1. Hierarchical control approach

In order to increase the system capacity or the availability of the machines, we assume that the transition rate from the operational mode to the preventive maintenance mode for each machine is a control variable called $\omega_{\mathrm{i}}(\mathrm{t}), \mathrm{i}=1, \cdots, \mathrm{m}$. The inverse of the control variable $\omega_{i}(t)$ represents the expected delay between the call for the technician and his arrival as defined by Boukas and Haurie (1990).

Let $\left\{\mathrm{Z}^{\alpha}(\mathrm{t}), \mathrm{t} \geq 0\right\}, \alpha \in \mathrm{B}$, be a finite-state stochastic process corresponding to the number of operational machines at time $t$ with values in $\varepsilon=\{0,1, \cdots, \mathrm{m}\}$. Let $\mathrm{u}=\left(\mathrm{u}_{1}, \cdots, \mathrm{u}_{\mathrm{n}}\right)^{\prime}$ denotes the vector of production rates. The set of the feasible control policies $\mathrm{K}(\mathrm{z})$, with $\mathrm{z}=\mathrm{Z}^{\alpha}(\mathrm{t})$, depend on the process $\zeta^{€}(\mathrm{t})$, and is given by: 


$$
\mathrm{K}(\mathrm{z})=\left\{\begin{array}{l}
(\mathrm{u}(\mathrm{t}), \omega(\mathrm{t})) \in \mathfrak{R}^{\mathrm{n}+\mathrm{m}}, \mathrm{u}_{\mathrm{i}}(\mathrm{t}) \geq 0, \sum_{\mathrm{p}=1}^{\mathrm{n}} \mathrm{u}_{\mathrm{p}}(\mathrm{t}) \gamma_{\mathrm{p}} \leq \mathrm{z}, \quad \mathrm{u}_{\mathrm{p}}=\sum_{\mathrm{i}=1}^{\mathrm{m}} \mathrm{u}_{\mathrm{ip}} \\
\text { and } 0 \leq \omega_{\mathrm{j}}(\mathrm{t}) \leq \omega_{\max }
\end{array}\right\} 0 \leq \mathrm{z} \leq \mathrm{m}
$$

where $\gamma_{p}$ is the processing time of the part-type $p$ and $\omega_{\max }$ is the maximal preventive maintenance rate of each machine.

The system behaviour is described by a hybrid state comprising both a discrete and a continuous component. The discrete component consists of the discrete event stochastic process $\zeta^{\epsilon}(\mathrm{t})$. The continuous component consists of continuous variables $\mathrm{x}=\left(\mathrm{x}_{1}, \cdots, \mathrm{x}_{\mathrm{n}}\right)^{\prime}$ and $\mathrm{a}=\left(\mathrm{a}_{1}, \cdots, \mathrm{a}_{\mathrm{m}}\right)^{\prime}$ corresponding to the inventory/backlog of products and the cumulative ages of machines. These state variables are described by the following differential equations:

$$
\begin{array}{ll}
\dot{\mathrm{x}}(\mathrm{t})=\mathrm{u}(\mathrm{t})-\mathrm{d} & \mathrm{x}(0)=0 \\
\dot{\mathrm{a}}(\mathrm{t})=\mathrm{f}(\mathrm{u}(\mathrm{t})) & \mathrm{a}(0)=\mathrm{a}
\end{array}
$$

where $x, a$ and $d$ are given initial surplus or backlog, initial machines ages and demand rates vectors respectively. Let $\widetilde{\mathrm{x}}=(\mathrm{x}, \mathrm{a})$ and $\widetilde{\mathrm{u}}=(\mathrm{u}, \omega)$.

Let $G(\alpha, \widetilde{x}, \widetilde{u})$ be the cost rate defined as follow:

$$
\mathrm{G}(\alpha, \widetilde{\mathrm{x}}, \widetilde{\mathrm{u}})=\mathrm{c}^{+} \mathrm{x}^{+}+\mathrm{c}^{-} \mathrm{x}^{-}+\mathrm{c}^{\alpha}, \quad \forall \alpha \in \varepsilon
$$

where $\mathrm{c}^{+}$and $\mathrm{c}^{-}$are costs incurred per unit produced parts for positive inventory and backlog respectively, $\mathrm{x}^{+}=\left(\max \left(0, \mathrm{x}_{1}\right), \cdots, \max \left(0, \mathrm{x}_{\mathrm{n}}\right)\right)^{\prime}$, $\mathrm{x}^{-}=\left(\max \left(-\mathrm{x}_{1} 0\right), \cdots, \max \left(-\mathrm{x}_{\mathrm{n}} 0\right)\right)^{\prime}$ and $\mathrm{c}^{\alpha}$ are given constants. 
Our objective is to control the production rate $\mathrm{u}(\mathrm{t})$ and the preventive maintenance rate $\omega(\mathrm{t})$ (or the control policy $\widetilde{\mathrm{u}}(\mathrm{t})$ ) so as minimize the expected discounted cost given by :

$$
J^{\varepsilon}(\alpha, \widetilde{x}, u)=E\left\{\int_{0}^{\infty} e^{-p t} G(\alpha, \widetilde{x}, u) d t \mid x(0)=x, a(0)=a, Z^{\varepsilon}(0)=\alpha\right\}
$$

subject to constraints given by equations (1) to (6). The value function of such a problem is :

$$
v^{\in}(\alpha, \widetilde{\mathrm{x}})=\inf _{\widetilde{\mathrm{u}} \in \mathrm{K}(\alpha)} \mathrm{J}^{\in}(\alpha, \widetilde{\mathrm{x}}, \widetilde{\mathrm{u}}) \quad \forall \alpha \in \varepsilon
$$

In the next sections, we present the elementary properties of the value function $v^{\in}($.$) and$ the derivation of the limiting control problem as $\varepsilon$ goes to 0 . 


\section{PROPERTIES OF THE VALUE FUNCTION}

In this section, we present some properties of the value function $v^{€}($.$) by using the$ method of viscosity solution of HJB equations. The dynamic programming equations, known as HJB equations, associated with the optimal control problem under study can be written formally as follows :

$$
\rho v^{\in}(\alpha, \widetilde{x})=\min _{\tilde{u} \in K(\alpha)}\left\{(u-d) v_{x}^{\in}(\alpha, \widetilde{x})+f(u) v_{a}^{\in}(\alpha, \widetilde{x})+G(\alpha, \widetilde{x}, \widetilde{u})+\frac{1}{\in} \sum_{\beta=0}^{m} q_{\alpha \beta} v^{\in}(\beta, \widetilde{x})\right\}
$$

for all $\alpha \in \varepsilon$. In what follows, we show that the value function $v^{\in}(\alpha,$.$) is locally$ Lipschitz and is the viscosity solution of the HJB equations.

The reader is referred to Sethi et al. (1998) for some results concerning convex functions. Before we move on, we give some definitions. For any function $f(\cdot): R \rightarrow R$, the super differential $D^{+} f(\widetilde{x})$ and the sub differential $D^{-} f(\widetilde{x})$ are defined respectively as follows :

$$
\begin{aligned}
& D^{+} f(\widetilde{x})=\left\{r \in R^{n+m}: \limsup _{h \rightarrow 0} \frac{f(\widetilde{x}+h)-f(\widetilde{x})-h \cdot r}{|h|} \leq 0\right\} \\
& D^{-} f(\widetilde{x})=\left\{r \in R^{n+m}: \liminf _{h \rightarrow 0} \frac{f(\widetilde{x}+h)-f(\widetilde{x})-h \cdot r}{|h|} \geq 0\right\}
\end{aligned}
$$

Definition 3.1. The value function $v^{\in}($.$) is a viscosity solution of (9) if the following$ conditions hold : $v^{\in}($.$) is continuous and 0 \leq v^{\in}(\alpha, \widetilde{\mathrm{x}}) \leq \mathrm{C}\left(1+|\widetilde{\mathrm{x}}|^{\mathrm{C}_{k}}\right)$;

$$
\begin{gathered}
\forall r \in D^{+} v^{\epsilon}(\alpha, \widetilde{x})=\left\{r \in R^{m+n}:\left.\lim \sup _{h \rightarrow 0}\left[v^{\in}(\alpha, \widetilde{x}+h)-v^{\epsilon}(\alpha, \widetilde{x})-\widetilde{h} \cdot r\right] h\right|^{-1} \leq 0\right\} \\
\rho v^{\epsilon}(\alpha, \widetilde{x}) \leq \min _{\widetilde{u} \in K(\alpha)}\left\{f(.) r+G(\alpha, \widetilde{x}, \widetilde{u})+\frac{1}{\in} \sum_{\beta=0}^{m} q_{\alpha \beta} v^{\epsilon}(\beta, \widetilde{x})\right\}
\end{gathered}
$$




$$
\begin{gathered}
\forall \mathrm{r} \in \mathrm{D}^{-} v^{\in}(\alpha, \widetilde{\mathrm{x}})=\left\{\mathrm{r} \in \mathrm{R}^{\mathrm{m}+\mathrm{n}}:\left.\liminf _{\mathrm{h} \rightarrow 0}\left[v^{\in}(\alpha, \widetilde{\mathrm{x}}+\mathrm{h})-v^{\in}(\alpha, \widetilde{\mathrm{x}})-\widetilde{\mathrm{h}} \cdot \mathrm{r}\right] \mathrm{h}\right|^{-1} \leq 0\right\} \\
\rho v^{\in}(\alpha, \widetilde{\mathrm{x}}) \geq \min _{\widetilde{\mathrm{u}} \in \mathrm{K}(\alpha)}\left\{\mathrm{f}(.) \mathrm{r}+\mathrm{G}(\alpha, \widetilde{\mathrm{x}}, \widetilde{\mathrm{u}})+\frac{1}{\in} \sum_{\beta=0}^{\mathrm{m}} \mathrm{q}_{\alpha \beta} v^{\in}(\beta, \widetilde{\mathrm{x}})\right\}
\end{gathered}
$$

where $f()=.(u-d, f(u))^{\prime}$.

A similar definition can be found in Clarke (1983). For more information and discussions on viscosity solutions, we refer the reader to Sethi et Zhand (1994a) and references therein.

Theorem 3.1. The value function $v^{\in}(\alpha, \widetilde{x}), \alpha \in \varepsilon$, defined in (8), is the only viscosity solution of the dynamic programming equations (9).

Proof. The proof of this theorem can be found in Kenne (1987) and Sethi and Zhang (1994b).

Let us now present a verification theorem that provides a sufficient condition for optimal control.

Theorem 3.2. (Verification Theorem) Let

$$
H\left(\alpha, x, v(x, \cdot), v_{x}(x, \alpha), u, \omega\right)=(u-d) v_{x}^{\varepsilon}(\alpha, \widetilde{x})+G(\alpha, \widetilde{x}, \widetilde{u})+\frac{1}{\in} \sum_{\beta=0}^{m} q_{\alpha \beta} v^{\in}(\beta, \widetilde{x})
$$

with $v(\alpha, x)$ denoting the differentiable solution of the HJB equations (9) such that :

$$
0 \leq v(\mathrm{x}, \alpha) \leq \mathrm{C}\left(1+|\mathrm{x}|^{\mathrm{C}_{\mathrm{k}}}\right)
$$

Then

i) $\quad v(\mathrm{x}, \alpha) \leq \mathrm{J}(\mathrm{x}, \alpha, \mathrm{u}(\cdot), \omega(\cdot)$ for all $(\mathrm{u}(\cdot), \omega(\cdot)) \in \mathrm{K}(\alpha))$ 
ii) If $\left(\mathrm{u}^{*}(\mathrm{x}, \alpha), \omega^{*}(\mathrm{x}, \alpha)\right)$ is an admissible feedback control such that :

$\min _{(u, \omega) K(\alpha)} H\left(\alpha, x, v(x, \cdot) v_{x}(x, \alpha), u, \omega\right)=H\left(\alpha, x, v(x, \cdot), v_{x}(x, \alpha), u_{*}(x, \alpha), \omega_{*}(x, \alpha)\right)$

then :

$$
\mathrm{J}\left(\mathrm{x}, \alpha, \mathrm{u}^{*}(\cdot), \omega^{*}(\cdot)\right)=\mathrm{v}(\mathrm{x}, \alpha)
$$

with $\left(\mathrm{u}^{*}(\cdot), \omega^{*}(\cdot)\right)=\left(\mathrm{u}^{*}(\mathrm{x}(\cdot), \alpha(\cdot)), \omega^{*}(\mathrm{x}(\cdot), \alpha(\cdot))\right)$

Thus $\left(\mathrm{u}^{*}(\cdot), \omega^{*}(\cdot)\right)$ is optimal

Proof. The proof of this theorem can be found in Boukas et al. (1995a).

The optimal control policy $\left(\mathrm{u}^{*}(\cdot), \omega^{*}(\cdot)\right)$ is the solution of HJB equations described by (9). Given the large size of (9) for multiple-machine, multiple-part-type manufacturing system, one need here to proceed to the reduction of the system size through the limiting control problem. 


\section{LIMITING CONTROL PROBLEM}

We derive here two equivalent formulations of the limiting problem in order to show that the value function of the initial stochastic problem converges to one of the related deterministic control problem. Let $v(\widetilde{x})=\lim _{\epsilon \rightarrow 0} v^{\in}(\alpha, \widetilde{x})$. The proposed approach is based on the stationary distribution of the stochastic process, computed here in terms of the mean values of the machines ages and preventive maintenance rates.

Let $\mathrm{a}_{\mathrm{M}}$ and $\bar{\omega}$ denote the mean values of the machines ages and preventive maintenance rates respectively. If $\mathrm{a}_{\mathrm{i}}$ and $\omega_{\mathrm{i}}, \mathrm{i}=1, \cdots, \mathrm{m}$, are replaced in the model by $\mathrm{a}_{\mathrm{M}}$ and $\bar{\omega}$, one obtain a constant transition rates matrix $\mathrm{Q}\left(\mathrm{a}_{\mathrm{M}}, \bar{\omega}\right)$. The finite state Markov chain associated to such a matrix is then homogeneous with stationary or limiting probabilities $v=\left(v_{1}, v_{2}, \cdots, v_{M}\right)^{\prime}$ given by :

$$
v Q(.)=0 \text { and } \sum_{i=1}^{M} v_{i}=1
$$

With these probabilities, the convergence property of the initial stochastic control problem to the limiting problem when $\varepsilon \rightarrow 0$ is established in Soner (1993). Let us now discuss on the meaning and determination of the mean value of a machine.

In early works we have proposed models for the planning of the production and maintenance problem (see Kenne et al. (1997), Kenne and Gharbi (1999) and Gharbi and Kenne (2000)) related to small size manufacturing systems. In all the models proposed, we used the fact that the stock level, $\mathrm{x}(\cdot)$, and the aging, $\mathrm{a}(\cdot)$, are described by differential equations of the types given by (4) and (5) respectively. Based on those models, we obtained that there exist two critical age value $A_{i}$ and $B_{i}$, for a machine $i$, $\mathrm{i}=1, \cdots, \mathrm{m}$, defined as follow : 
$\mathrm{A}_{\mathrm{i}} \quad$ The age of the machine $\mathrm{i}$ at which it is necessary to stock parts. Before this age, the machine is assumed to be new, and a production at the demand rate is suggested if the other machines are new.

$\mathrm{B}_{\mathrm{i}} \quad$ The age at which the machine $\mathrm{i}$ is sent to preventive maintenance when a comfortable level of inventory is achieved. In such a situation, the machine will be sent to preventive maintenance randomly (i.e., there is a random delay from the machine age $B_{i}$ to the maintenance time).

By assuming that the jump rates are functions of the age a(.), we model correctly the fact that the more we use a machine, the more its probability to failure will increase with age. Hence, we assume herein that the mean value of a machine age aM is between $A_{i}$ and $\mathrm{B}_{\mathrm{i}}$.

This assumption has been verified through off-line simulation experiments. Note that negative inventories are minimised by setting $a_{M}$ to $A_{i}$. However, this is not necessary the best way to select such a value. We usually resort to simulation modelling as in Pritsker et al. (1997) to determine the mean age value for a given machine.

By using equation (10) and multiplying both side of (9), at $\alpha=\mathrm{i}$, by $v_{\mathrm{i}}($.$) and sum over$ $i \in \varepsilon$, we have :

$$
\rho \sum_{i=0}^{m} v_{i} v^{\varepsilon}(i, x)=\sum_{i=0}^{m} v_{i} \min _{\widetilde{u} \in K(i)}\left\{\left(u^{i}-d\right) v_{x}^{\in}(i, \widetilde{x})+f\left(u^{i}\right) v_{a_{M}}^{\in}(i, \widetilde{x})+G\left(i, \widetilde{x}, \widetilde{u}^{i}\right)\right\}
$$

Let $\in \rightarrow 0$, one have

$$
\rho v(i, \widetilde{x})=\sum_{i=0}^{m} v_{i} \min _{\widetilde{u} \in K(i)}\left\{\left(u^{i}-d\right) v_{x}^{\in}(\widetilde{x})+f\left(u^{i}\right) v_{a_{M}}^{\epsilon}(\widetilde{x})+G\left(i, \widetilde{x}, \widetilde{u}^{i}\right)\right\}
$$

Let us define a deterministic control process $\mathrm{U}(\mathrm{t})$ in a control space $\mathrm{A}^{0}$ given by : 


$$
\mathrm{A}^{0}=\left\{\begin{array}{c}
\mathrm{U}(\mathrm{t})=\left(\left(\mathrm{u}^{0}(\mathrm{t}), \bar{\omega}^{0}(\mathrm{t})\right)\right),\left(\mathrm{u}^{1}(\mathrm{t}), \bar{\omega}^{1}(\mathrm{t})\right), \ldots,\left(\mathrm{u}^{\mathrm{m}}(\mathrm{t}), \bar{\omega}^{\mathrm{m}}(\mathrm{t})\right): 0 \leq \mathrm{p}=\sum_{\mathrm{p}=1}^{\mathrm{n}} \gamma_{\mathrm{p}} \mathrm{u}_{\mathrm{p}}^{\mathrm{i}}(\mathrm{t}) \leq \mathrm{i}, \\
0 \leq \bar{\omega}^{\mathrm{i}}(\mathrm{t}) \leq \omega_{\max }
\end{array}\right\}
$$

We define the control problem $\mathrm{P}^{0}$ as follows :

$$
\min J^{0}(\widetilde{x}, U(.))=E \int_{0}^{\infty} e^{-\rho t} \sum_{i=0}^{m} v_{i} G\left(i, \widetilde{x}(t), \widetilde{u}^{i}(t)\right) d t
$$

subject to

$$
\begin{array}{cc}
\dot{x}=\sum_{i=0}^{m} v_{i} u^{i}(t)-d & x(0)=x \\
\dot{a}_{M}=\sum_{i=0}^{m} v_{i} f\left(u^{i}(t)\right) & a_{M}(0)=a_{M}
\end{array}
$$

with the value function given by

$$
v(\widetilde{x})=\inf _{U(.) \in A^{0}} J^{0}(\widetilde{x}, U(.))
$$

The structure of (12) suggests us another formulation of the limiting problem. This is done by replacing $\mathrm{Z}^{\epsilon}(\mathrm{t})$, or $\mathrm{i} \in \mathrm{B}$, by $\overline{\mathrm{k}}\left(\overline{\mathrm{a}}_{\mathrm{M}}, \bar{\omega}\right)=\mathrm{E}\left[\mathrm{Z}^{\epsilon}(\mathrm{t})\right]=\sum_{\mathrm{i}=0}^{\mathrm{m}} \mathrm{i} \mathrm{v}_{\mathrm{i}}($.$) . For any \mathrm{r} \in \mathrm{R}^{\mathrm{m}+1}$, we then have

$$
\sum_{i=0}^{m} v_{i} \min _{\tilde{u} \in K(i)}\left\{f\left(\widetilde{u}^{i}\right) \cdot r+G\left(i, \widetilde{x}, \widetilde{u}^{i}\right)\right\}=\min _{\widetilde{u} \in K(\bar{k}(\cdot))}\{f(\widetilde{\widetilde{u}}) \cdot r+\bar{G}(\widetilde{x}, \overline{\widetilde{u}})\}
$$

with $\overline{\mathrm{G}}(\mathrm{x}, \overline{\widetilde{\mathrm{u}}})=\sum_{\mathrm{i}=0}^{\mathrm{m}} \mathrm{v}_{\mathrm{i}} \mathrm{G}(\mathrm{i}, \mathrm{x}, \overline{\widetilde{\mathrm{u}}})$ and $\overline{\widetilde{\mathrm{u}}}=(\overline{\mathrm{u}}, \omega)$ where $\overline{\mathrm{u}}=\sum_{\mathrm{i}=0}^{\mathrm{m}} \mathrm{v}_{\mathrm{i}} \mathrm{u}^{\mathrm{i}}(\mathrm{t})$. The equation (17) is derived with the conjecture of the linearity of $f($.$) on u$. The equation (12) can then be written as 


$$
\rho v(\widetilde{x})=\min _{\widetilde{\mathrm{u}} \in \mathrm{K}(\overline{\mathrm{k}}(.))}\left\{(\overline{\mathrm{u}}-\mathrm{d}) v_{\mathrm{x}}(\widetilde{\mathrm{x}})+\mathrm{k} \overline{\mathrm{u}} \mathrm{v}_{\mathrm{a}_{\mathrm{M}}}(\widetilde{\mathrm{x}})+\overline{\mathrm{G}}(\widetilde{\mathrm{x}}, \overline{\widetilde{u}})\right\}
$$

The alternative formulation of the limiting problem, $\widetilde{\mathrm{P}}^{0}$, can then be defined by :

$$
\min \widetilde{J}^{0}(\widetilde{x}, \widetilde{\widetilde{u}}(.))=\int_{0}^{\infty} \mathrm{e}^{-\rho t} \overline{\mathrm{G}}(\widetilde{\mathrm{x}}, \widetilde{\widetilde{u}}) \mathrm{dt}
$$

subject to

$$
\begin{aligned}
& \dot{x}=\bar{u}(t)-d \quad x(0)=x \\
& \dot{a}_{M}=k \bar{u} \quad a_{M}(0)=a_{M}
\end{aligned}
$$

with the value function given by

$$
\widetilde{v}(\widetilde{\mathrm{x}})=\inf _{\widetilde{\mathrm{u}} \in \widetilde{\mathrm{A}}^{0}} \widetilde{\mathrm{J}}^{0}(\widetilde{\mathrm{x}}, \widetilde{\widetilde{\mathrm{u}}}(.))
$$

The value function $\widetilde{v}(\widetilde{x})$ is equivalent to $v(\widetilde{x})$ and can be shown to be the only viscosity solution of (18) (cf. theorem 3.1). It is interesting to note that the obtained limiting problem does not depend on the explicit form of $\mathrm{Q}($.$) , only on \overline{\mathrm{k}}(\mathrm{a}, \omega)$, which is the mean machine availability. This makes the limiting problem very simpler to solve.

Given that the previous equations was obtained for given $\bar{\omega}$, the overall optimization problem can be described by the following deterministic HJB equations :

$$
\rho v(\widetilde{x})=\min _{0 \leq \bar{\omega} \leq \bar{k} \omega_{\max }}\left\{\min _{\overline{\mathrm{u}} \in \mathrm{K}(\overline{\mathrm{k}}(.))}\left[(\overline{\mathrm{u}}-\mathrm{d}) \mathrm{v}_{\mathrm{x}}(\widetilde{\mathrm{x}})\right]+\frac{1}{\mathrm{~m}}\left(\sum_{\mathrm{j}=1}^{\mathrm{n}} \mathrm{k}_{\mathrm{j}} \mathrm{d}_{\mathrm{j}}\right) \mathrm{v}_{\mathrm{a}_{\mathrm{M}}}(\tilde{\mathrm{x}})+\overline{\mathrm{G}}(\tilde{\mathrm{x}}, \bar{\omega})\right\}
$$

Based on the structure of the stochastic control presented in Boukas and Haurie (1990) and Kenne (1997), we provide a machine age dependent control policy through the solution of (23). The following method is applied to build such a policy. 
- Consider an equivalent machine and let $\overline{\mathrm{a}}_{\mathrm{m}}$ be its age mean value, called here equivalent machine mean age.

- Select $\delta$ and $\mathrm{a}_{\mathrm{M}}$ to define the following set of equivalent machine mean age values.

$$
\Omega=\left\{\overline{\mathrm{a}}_{\mathrm{m}}: \mathrm{a}_{\mathrm{M}}-\delta \leq \overline{\mathrm{a}}_{\mathrm{m}} \leq \mathrm{a}_{\mathrm{M}}+\delta\right\}
$$

- How to determine machine age dependent preventive maintenance and production rates

(i) For any $\mathrm{a}_{\mathrm{i}}(\mathrm{t}) \in \Omega, \mathrm{i}=1, \cdots, \mathrm{m}$, set the maintenance rate to the one of the limiting problem if there is a significant stock level. The production rate is then set to its maximal value.

(ii) For any $\mathrm{a}_{\mathrm{i}}(\mathrm{t})<\mathrm{a}_{\mathrm{M}}-\delta, \mathrm{i}=1, \cdots, \mathrm{m}$, the machine $i$ is supposed to be new. Hence, the preventive maintenance rate is set to zero and the production rate is set to the demand rate.

(iii) For any $\mathrm{a}_{\mathrm{i}}(\mathrm{t})>\mathrm{a}_{\mathrm{M}}+\delta, \mathrm{i}=1, \cdots, \mathrm{m}$, the machine $i$ is supposed to be old. The preventive maintenance and production rates are set to their maximal values.

Such a method is used in the next section to determine the age dependent control policy for the limiting problem. 


\section{HEURISTICAL OPTIMAL FEEDBACK CONTROL}

From the solution of the limiting problem, it has been shown in Lehoczky et al. (1991) how to construct a near-optimal control policy of the original stochastic control problem in the case of homogeneous Markov processes. With such a process, the control policy consists of the production rate and is approximated in Lehoczky et al. (1991) by the following theorem :

Theorem 5.1. If $\bar{u}^{*}($.$) is the optimal production rate of the limiting problem related to$ the homogeneous Markov process, one can approximate the optimal production rate related to the stochastic original problem by the following equation :

$$
\mathrm{u}(\widetilde{\mathrm{x}}, 1)=1 \frac{\overline{\mathrm{u}}^{*}(\widetilde{\mathrm{x}})}{\overline{\mathrm{v}}(.)} \quad 0 \leq 1 \leq \mathrm{m}
$$

where 1 is the number of operational machines. The production rate of the operational machine $i$ at mode $\alpha$ is given by :

$$
\mathrm{u}_{\mathrm{i}}(\widetilde{\mathrm{x}}, \alpha)=\frac{\mathrm{u}(\widetilde{\mathrm{x}}, 1)}{\alpha} \quad 0 \leq \alpha \leq \mathrm{m}
$$

Proof. The proof of this theorem is presented in Lehoczky et al. (1991).

This theorem states that the production rate of a FMS is equally distributed to operational machines at a given time. The proposal of this paper is mainly based on the machine age and control dependent dynamics of the machines modes (i.e., non homogeneous Markov process). Thus initial identical machines become different while producing due to the fact that their age's trajectories are obviously different. With such an observation, theorem 5.1 cannot be generally valid for the construction of a stochastic near-optimal control when the age is introduced in the model. 
Given that the control policy is age dependent in the case considered herein, we first proceed with the numerical solution of (23) for a two-machine, one-product system $(m=2$ and $n=1)$, to illustrate the structure of the optimal stochastic control policy. From such a structure, we will next derive and heuristical method for the construction of a near-optimal control policy for a large class of FMS. The solution of (23) for large systems can be easily determined, as in section 6 , using numerical techniques. From the control policy of the two-machine, one-product FMS, derived from a numerical solution of equation (23) and the related age dependent control policy, it is interesting to observe the following :

- When there is a backlog (i.e., the surplus $\mathrm{x}(\mathrm{t})<0$ ), the production rates are set to their maximal values and the preventive maintenance rates are set to zero for both machines;

- When $x(t)=0$, the production rate of the FMS is either equal to the demand rate for small machines age's values or greater than the demand rate for large machines age's values.

- When there is an inventory (i.e., $\mathrm{x}(\mathrm{t})>0$ ), the machine with a higher age is frequently used compared with the new one. We note that the preventive maintenance domain decreases when the machines ages increase.

Based on these results, we propose the following heuristical method for the construction of near-optimal control policy for the original stochastic control problem.

Step 1. Consider a $q$-finite partition $\mathrm{C}_{0}, \mathrm{C}_{1}, \ldots, \mathrm{C}_{\mathrm{q}}$ which consists of $\mathrm{q}+1$ sets of machines ages values such that the dynamics of a machine age moves from $\mathrm{C}_{\mathrm{i}}$ to $\mathrm{C}_{\mathrm{i}+1}$ and from $\mathrm{C}_{\mathrm{k}},(\mathrm{k} \neq 0)$ to $\mathrm{C}_{0}$ after each intervention on the machine (repair or maintenance). The partition is such that :

$$
\bigcup_{i=0}^{q+1} C_{i}=\wedge \text { and } \bigcap_{i=0}^{q+1} C_{i}=\emptyset
$$


where $\wedge=\left\{a_{i}: a_{i}=(i-1) h_{a}\right\}, i=1, \ldots, N_{a}$ for given $N_{a}$ and $h_{a}$. Note that $\wedge$ is a onedimension grid of $\mathrm{N}_{\mathrm{a}}$ points generated by $\mathrm{h}_{\mathrm{a}}$. An example of partition is illustrated in figure 2 for $\mathrm{q}=1$ in the case of two-machine FMS.

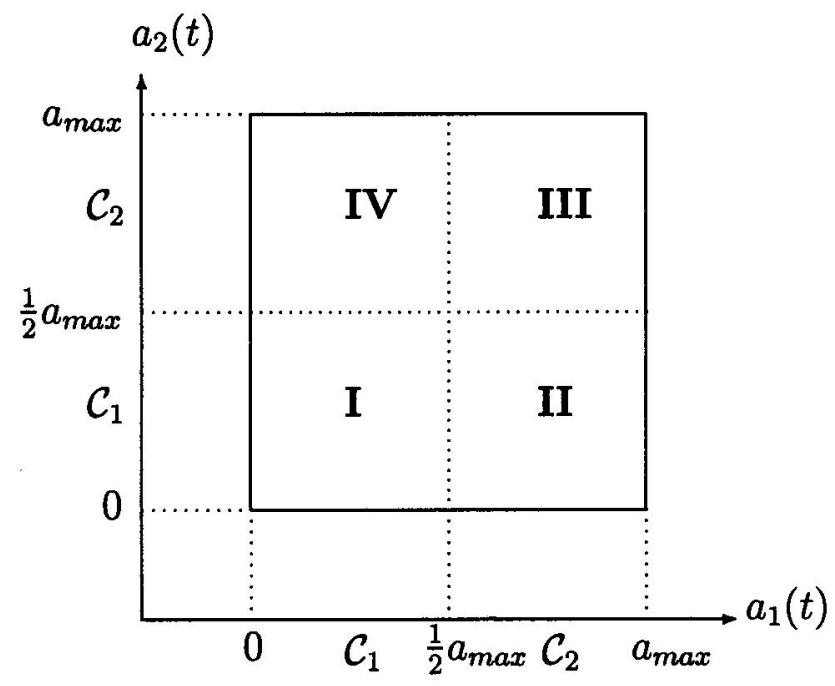

Figure 2. Classes of operational machines

Step 2. At a given time, group operational machines in classes and apply theorem 5.1 (equations (25) and (26)) for machines in the same class. A class here correspond to a set $\mathrm{C}_{\mathrm{k}}, 0 \leq \mathrm{k} \leq \mathrm{q}$, of the partition mentioned in step 1 . It is assumed here that machines in the same class are identical.

Step 3. Use frequently old machines such that the sum of production rates remains close to the solution of the limiting problem when the involved machines are in different classes. The production rates $\mathrm{u}(\alpha, \widetilde{\mathrm{x}})$ of the FMS still given by the equation (25). When $\mathrm{x}(\mathrm{t})>0$ and $\overline{\widetilde{u}}() \neq$.0 , one can distribute $\mathrm{u}(\alpha, \widetilde{\mathrm{x}})$ to operational machines using the following steps : 
(i) For a given mode $\alpha$, classify the operational machines through a decreasing order (beginning with the oldest machine, followed with the closely second, and so on). Let $O$ denote the set of ordered machines.

(ii) Set a maximal value to the production rate of the oldest machine and assign sequentially the maximal production rate or the demand rate to other machines until the sum of assigned production rates reaches the production rate $\widetilde{\mathrm{u}}(\alpha, \widetilde{\mathrm{x}})$. Assign zero to the production rates of the remaining machines.

(iii) Repeat steps (i) and (ii) for all $\alpha \in\{1, \cdots, m\}$.

Step 4. At the mode $\alpha=\mathrm{m}$ (i.e., all machines are operational), the preventive maintenance policy of the stochastic problem can be approximated by assigning maximal preventive maintenance rate to the oldest machine and compare the sum of assigned preventive maintenance rates to $\omega(\alpha, \widetilde{\mathrm{x}})$. Continue with the assignment process until the sum of assigned rates reaches $\omega(\alpha, \widetilde{x})$ and then assign 0 to the preventive maintenance rates of the remaining machines.

We will use this method in the next section in order to construct a near-optimal control policy for the numerical example developed in that section. 


\section{EXPERIMENTATION OF THE PROPOSED APPROACH}

We give a two-machine two-part-type model as an example for the numerical experiment $(\mathrm{m}=2$ and $\mathrm{n}=2)$. With such a model, we have :

$$
\begin{array}{ll}
\dot{\mathrm{x}}_{\mathrm{j}}=\mathrm{u}_{1 \mathrm{j}}(\mathrm{t})+\mathrm{u}_{2 \mathrm{j}}(\mathrm{t})-\mathrm{d}_{\mathrm{j}} \quad \mathrm{x}_{\mathrm{j}}(0)=\mathrm{x}_{\mathrm{j}}, \quad \mathrm{j}=1,2 \\
\dot{\mathrm{a}}_{\mathrm{i}}=\mathrm{k}_{\mathrm{a}}\left(\mathrm{u}_{\mathrm{i} 1}(\mathrm{t})+\mathrm{u}_{\mathrm{i} 2}(\mathrm{t})\right)_{\mathrm{j}} \quad \mathrm{a}_{\mathrm{i}}(0)=\mathrm{a}_{\mathrm{i}}, \quad \mathrm{i}=1,2
\end{array}
$$

In this case we have $\zeta^{€}(t) \in B=\{1,2, \cdots, 9\}$ and $Z(t) \in \varepsilon=\{0,1,2\}$. The transition rates $\mathrm{q}_{12}^{\mathrm{i}}$ depend on the machine age and are approximated by the equation :

$$
\mathrm{q}_{12}^{\mathrm{i}}(.)=\mathrm{q}_{\mathrm{o}}+\mathrm{q}_{\mathrm{a}} \times \mathrm{a}_{\mathrm{i}}(\mathrm{t}), \quad \mathrm{i}=1,2
$$

for given $\mathrm{q}_{\mathrm{o}}$ and $\mathrm{q}_{\mathrm{a}}$. The average number of operational machines is given by :

$$
\bar{v}(.)=E[Z(t)]=0 \times p_{0}+1 \times p_{1}+2 \times p_{2}
$$

with $p_{0}=v_{5}+v_{6}+v_{8}+v_{9}, p_{1}=v_{2}+v_{3}+v_{4}+v_{7}$ and $p_{1}=v_{1}$. The considered control problem is feasible if the following condition holds :

$$
\bar{v}(.)-d \geq 0
$$

The average cost function derived from equation (6) is given by :

$$
\overline{\mathrm{G}}(\mathrm{s}, \mathrm{u}, \omega)=\mathrm{c}^{+} \mathrm{x}^{+}+\mathrm{c}^{-} \mathrm{x}^{-}+\mathrm{c}^{2}\left(v_{2}+v_{4}+2 v_{5}+v_{6}+v_{8}\right)+\mathrm{c}^{3}\left(v_{3}+v_{6}+v_{7}+v_{8}+2 v_{9}\right)
$$

where $\mathrm{c}^{2}$ and $\mathrm{c}^{3}$ represent repair and maintenance cost activities respectively.

Equation (19) is subject here to the following state constraints : 


$$
\begin{gathered}
\dot{\mathrm{x}}_{1}(\mathrm{t})=\overline{\mathrm{u}}_{1}(\mathrm{t})-\mathrm{d}_{1} \quad \mathrm{x}_{1}(0)=\mathrm{x}_{1} \\
\dot{\mathrm{x}}_{2}(\mathrm{t})=\overline{\mathrm{u}}_{2}(\mathrm{t})-\mathrm{d}_{2} \quad \mathrm{x}_{2}(0)=\mathrm{x}_{2} \\
\dot{\mathrm{a}}_{\mathrm{M}}=\mathrm{k} \frac{1}{2}\left(\mathrm{k}_{1} \mathrm{a}_{1}+\mathrm{k}_{2} \mathrm{a}_{2}\right) \quad \mathrm{a}_{\mathrm{M}}(0)=\mathrm{a}_{M}
\end{gathered}
$$

where am is the mean value of the machines ages and $\mathrm{k}_{1}$ and $\mathrm{k}_{2}$ are given constants. The HJB equations (23) can be rewritten as follows :

$$
\begin{aligned}
\rho v(\widetilde{x})= & \min _{0 \leq \bar{\omega} \leq \bar{k} \omega_{\max }}\left\{\operatorname { m i n } _ { \overline { \mathrm { u } } \in \mathrm { K } ( \overline { \mathrm { k } } ) } \left\{\left(\overline{\mathrm{u}}_{1}-\mathrm{d}_{1}\right) \mathrm{v}_{\mathrm{x} 1}(\widetilde{\mathrm{x}})+\left(\overline{\mathrm{u}}_{2}-\mathrm{d}_{2}\right) \mathrm{v}_{\mathrm{x} 2}(\widetilde{\mathrm{x}})\right.\right. \\
& \left.\left.+\frac{1}{2}\left(\mathrm{k}_{1} \mathrm{~d}_{1}+\mathrm{k}_{2} \mathrm{~d}_{2}\right) \mathrm{v}_{\mathrm{a}_{\mathrm{M}}}(\widetilde{\mathrm{x}})+\overline{\mathrm{G}}\left(\mathrm{x}, \mathrm{a}_{\mathrm{M}}, \bar{\omega}\right)\right\}\right\}
\end{aligned}
$$

Let us now apply numerical methods to equation (37) in order to define the control policy of the limiting problem (i.e., $\left.\left(\overline{\mathrm{u}}_{1}, \overline{\mathrm{u}}_{2}, \bar{\omega}\right)\right)$.

By approximating partial derivatives in equation (37), we obtain, after a couple of manipulations, the following equation :

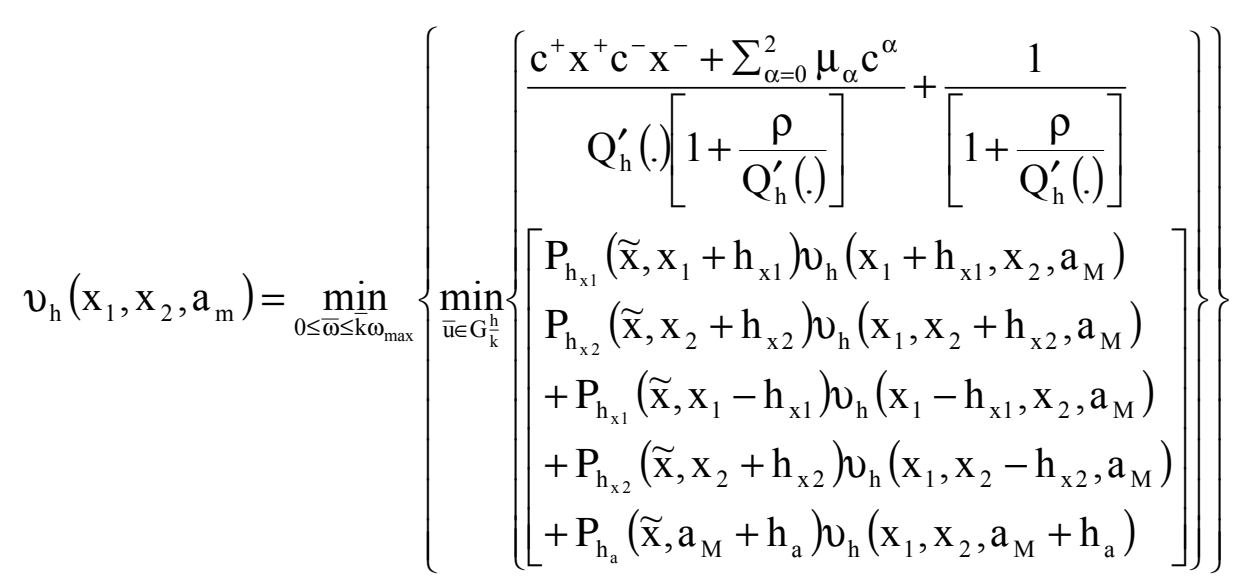


where $h_{x 1}, h_{x 2}$ and $h_{a}$ are discrete increments associated to state variables $x_{1}, x_{2}$ and $a_{m}$ respectively.

In addition, we have :

$$
\begin{gathered}
Q_{h}^{\prime}(.)=\frac{k_{1} d_{1}+k_{2} d_{2}}{2 h_{a}}+\frac{\left|\bar{u}_{1}-d_{1}\right|}{h_{x 1}}+\frac{\left|\bar{u}_{2}-d_{2}\right|}{h_{x 2}} \\
P_{h_{x 1}}\left(\widetilde{x}, x_{1}+h_{x 1}\right)=\left\{\begin{array}{cc}
\frac{\bar{u}_{1}-d_{1}}{h_{x 1} Q_{h}^{\prime}(.)} & \text { si } \bar{u}_{1}-d_{1} \geq 0 \\
0 & \text { otherwise }
\end{array}\right. \\
P_{h_{x 2}}\left(\widetilde{x}, x_{2}+h_{x 2}\right)=\left\{\begin{array}{cc}
\frac{\bar{u}_{2}-d_{2}}{h_{x 2} Q_{h}^{\prime}(.)} & \text { si } \bar{u}_{2}-d_{2} \geq 0 \\
0 & \text { otherwise }
\end{array}\right. \\
P_{\mathrm{h}_{x 1}}\left(\widetilde{x}, x_{1}-h_{x 1}\right)=\left\{\begin{array}{cc}
\frac{d_{1}-\bar{u}_{1}}{h_{x 1} Q_{h}^{\prime}(.)} & \text { si } \bar{u}_{1}-d_{1}<0 \\
0 & \text { otherwise }
\end{array}\right. \\
P_{h_{x 2}}\left(\widetilde{x}, x_{2}-h_{x 2}\right)=\left\{\begin{array}{cc}
\frac{d_{2}-\bar{u}_{2}}{h_{x 2} Q_{h}^{\prime}(.)} & \text { si } \bar{u}_{2}-d_{2}<0 \\
0 & \text { otherwise }
\end{array}\right. \\
P_{h_{a}}\left(\widetilde{x}, a_{M}+h_{a}\right)=\frac{k_{1} d_{1}+k_{2} d_{2}}{2 h_{a} Q_{h}^{\prime}(.)}
\end{gathered}
$$

Equation (38) is solved numerically using the following values :

1) $\quad \mathrm{h}_{\mathrm{x} 1}=\mathrm{h}_{\mathrm{x} 2}=\mathrm{h}_{\mathrm{a}}=0,2, \quad \mathrm{x}_{1}, \mathrm{x}_{2} \in[-2,2], \mathrm{a}_{\mathrm{M}} \in[0,6]$ and $\mathrm{u}_{\max }^{\mathrm{ij}}=1$.

2) Instantaneous cost (see table II)

Table II. Instantaneous cost parameters (two machines, two products)

\begin{tabular}{|c|l|l|l|l|l|l|l|l|l|l|l|l|l|l|}
\hline $\mathrm{c}_{1}^{+}$ & $\mathrm{c}_{1}^{-}$ & $\mathrm{c}_{2}^{+}$ & $\mathrm{c}_{2}^{-}$ & $\overline{\mathrm{c}}^{0}$ & $\overline{\mathrm{c}}^{1}$ & $\overline{\mathrm{c}}^{2}$ & $\overline{\mathrm{c}}^{3}$ & $\overline{\mathrm{c}}^{4}, \overline{\mathrm{c}}^{5}$ & $\overline{\mathrm{c}}^{6}$ & $\overline{\mathrm{c}}^{7}$ & $\overline{\mathrm{c}}^{8}$ & $\overline{\mathrm{c}}^{9}$ & $\mathrm{k}_{1}$ & $\mathrm{k}_{2}$ \\
\hline 1 & 10 & 1.1 & 10.2 & 0 & 10 & 1 & 20 & 10 & 1 & 11 & 11 & 2 & 2 & 2 \\
\hline
\end{tabular}


3)

$$
\begin{aligned}
& \text { 3) } \mathrm{d}_{1}=\mathrm{d}_{2}=1,6, \mathrm{\rho}=0,005, \mathrm{q}_{12}\left(\mathrm{a}_{\mathrm{i}}(\mathrm{t})\right)=\mathrm{A}_{0}+\mathrm{K}_{\mathrm{a}} \mathrm{a}_{\mathrm{i}}(\mathrm{t}) \text {, } \\
& \mathrm{i}=1,2 \text { with } \mathrm{A}_{0}=0,0001 \text { and } \mathrm{K}_{\mathrm{a}}=0,005 \\
& \text { 4) } \mathrm{q}_{21}=0,1 \text { and } \mathrm{q}_{31}=0,25
\end{aligned}
$$

With those data, the obtained control policy $\overline{\mathrm{u}}_{1}, \overline{\mathrm{u}}_{2}, \bar{\omega}$ is presented by figures 3,4 and 5 .

It is interesting to observe from the production policy that when $\left(\mathrm{c}_{2}^{+}>\mathrm{c}_{1}^{+}\right.$and $\left.\mathrm{c}_{2}^{-}>\mathrm{c}_{1}^{-}\right)$, machines are assigned to product $P_{1}$ if $x_{2} \geq 0$ (see figure 3). From figure 4 , the production of $\mathrm{P}_{2}$ is maximal for $\mathrm{x}_{2}<0$. A production at the maximal rate is recommended for $x_{2} \geq 0$. This is also valid near $x_{2}=0, x_{1}>0$ in order to built an inventory. The production rate of $\mathrm{P}_{2}$ is then set to the demand rate for $x_{1} \geq 1$ and $x_{2}=0,2$.

Note that for $\mathrm{a}_{\mathrm{m}}=3.2$ and $\bar{\omega}=0,04$, the average of the maximal capacity of the system is 1,84 (see figures 3 and 4). Figure (5) shows that the preventive maintenance rate of the limiting problem is different from zero for significant stock levels (i.e., $x_{1}>0,6$ et $\left.x_{2}>0,6\right)$.

Let us now apply the heuristic method presented in section 5 to construct a machine age dependent control policy for the limiting problem. Figures 6 and 7 show that, for new machines, there is no need to built inventory. Conversely, significant stock levels are recommended for old machines (see figures 8 and 9).

From figure 10, note that the preventive maintenance rate is set to zero for small machine age values such as $a_{1}=1$ (i.e., the machine is supposed to be new). The situation is different for $a=5$, given that a preventive maintenance must be done for 
comfortable stock levels such as $\mathrm{x}_{2}>0,8$ et $\mathrm{x}_{1}>0,6$. This is clearly explained by figure 11 .

The previous age dependent control policy of the limiting problem has been successfully used to construct the stochastic optimal control of the original problem through the procedure described in section 5 . We provide here a set of figures to illustrate the main properties of the control policy related to the state variables $\mathrm{a}_{1}, \mathrm{a}_{2}, \mathrm{x}_{1}$ and $\mathrm{x}_{2}$ (see figures 12 to 17). Such a policy is the expansion of the machine age dependent limiting control policy obtained from the proposed heuristical control approach. It appears from the obtained control policy (figure 12 to 17 ) that, for a machine age greater than $A_{i}$, the structure of the optimal production policy could be given by :

$$
u_{j}(\widetilde{x})=\left\{\begin{array}{ccc}
u_{\max }^{j} & \text { si } & x_{j}(t)<X_{j} \\
d_{j} & \text { si } & x_{j}(t)=X_{j} \\
0 & \text { si } & x_{j}(t)>X_{j}
\end{array}\right.
$$

where $X_{j}$ is the threshold value of product $j$ and $u_{\max }^{j}=\sum_{i=1}^{m} u_{\max }^{i j}$ with $u_{\max }^{i j}$ describing the maximal production rate of product $j$ on machine $i$. Recall that $A_{i}$ is the age of the machine I at which it is necessary to stock parts. The optimal machine age dependent preventive maintenance policy depends on a machine a $B_{i}$ at which machine $I$ is sent to preventive maintenance when threshold values $X_{j}, j=1, \cdots, n$, are achieved. 


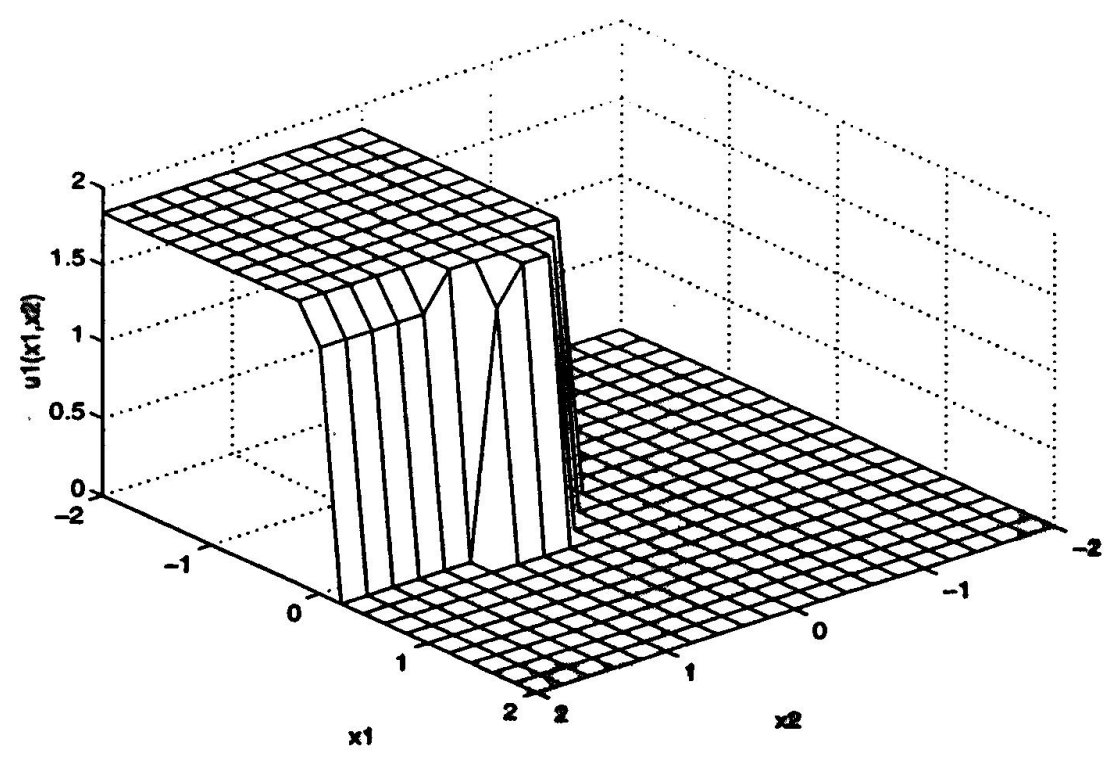

Figure 3: Production rate $\bar{u}_{1}\left(x_{1}, x_{2}\right)$ for product 1

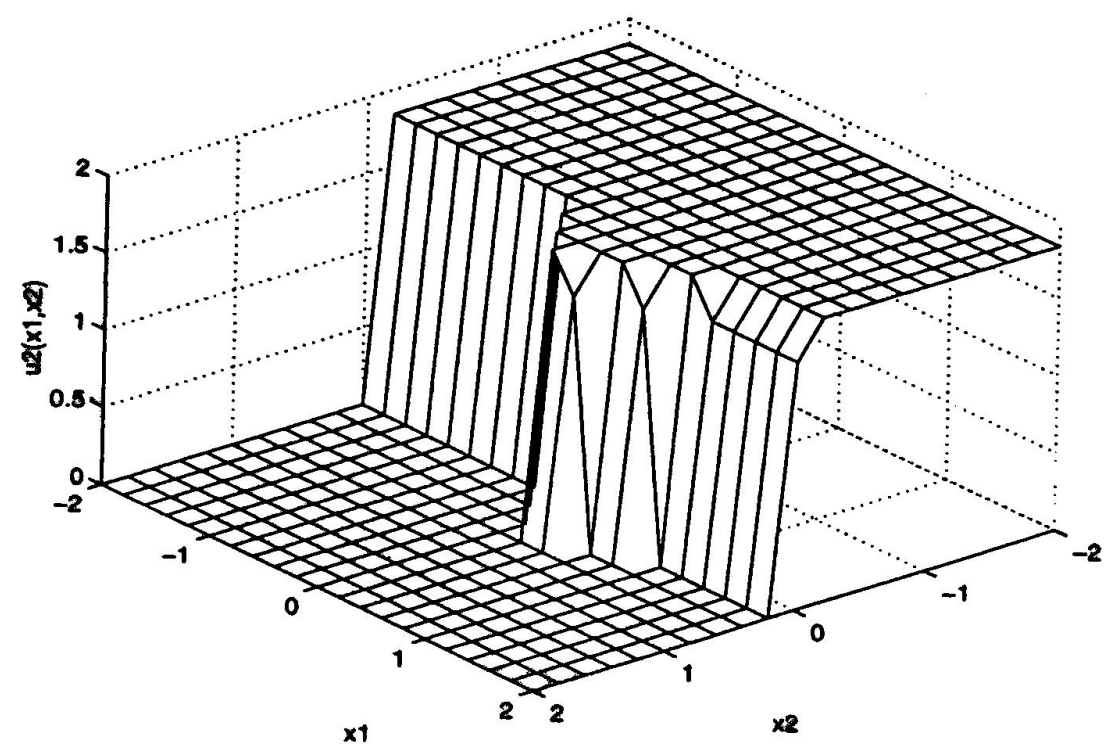

Figure 4: Production rate $\bar{u}_{2}\left(x_{1}, x_{2}\right)$ for product 2 


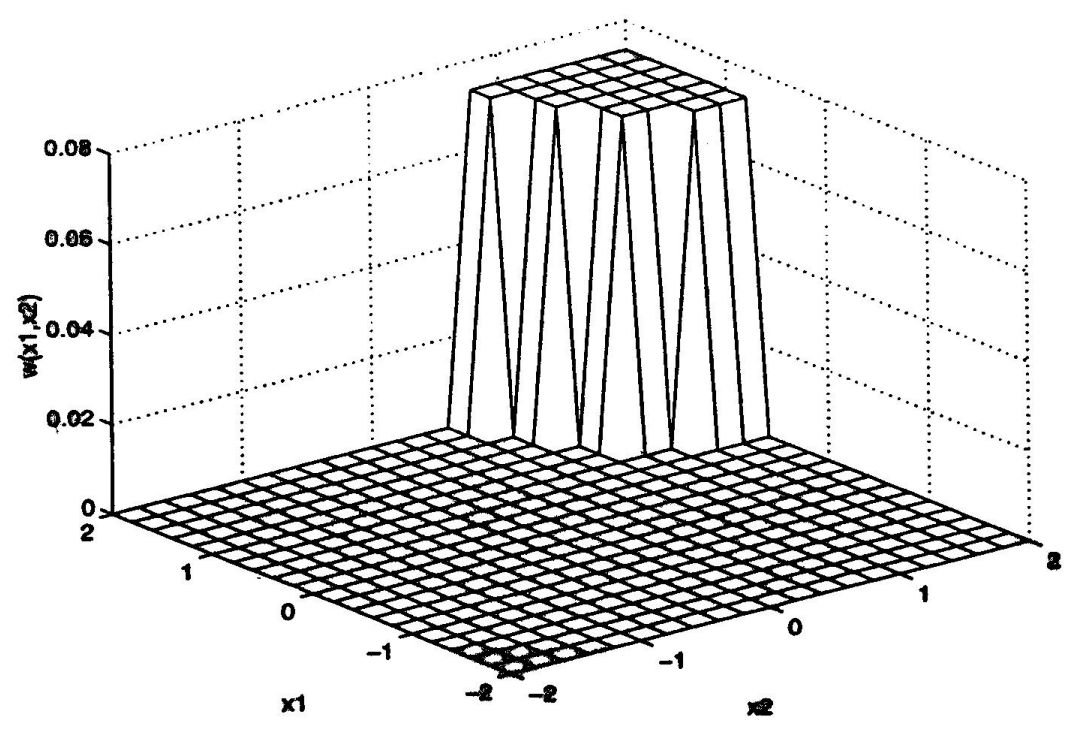

Figure 5: Preventive maintenance rate $\bar{\omega}\left(x_{1}, x_{2}\right)$ for the limiting problem

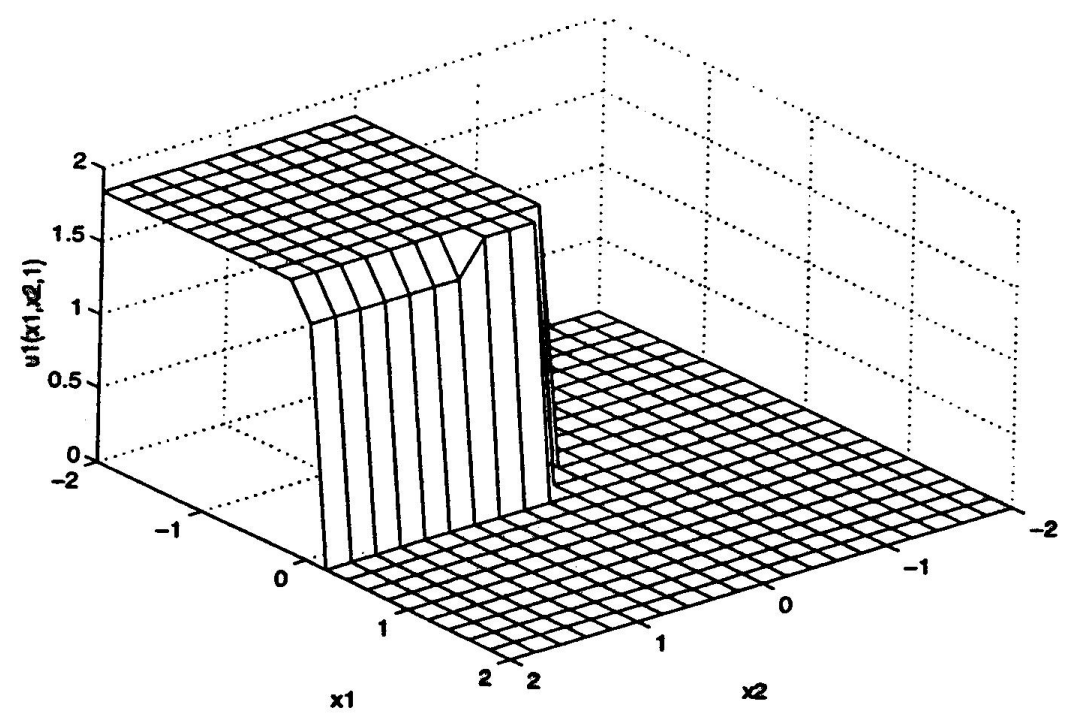

Figure 6: Production $\bar{u}_{1}\left(x_{1}, x_{2}, 1\right)$ for product 1 


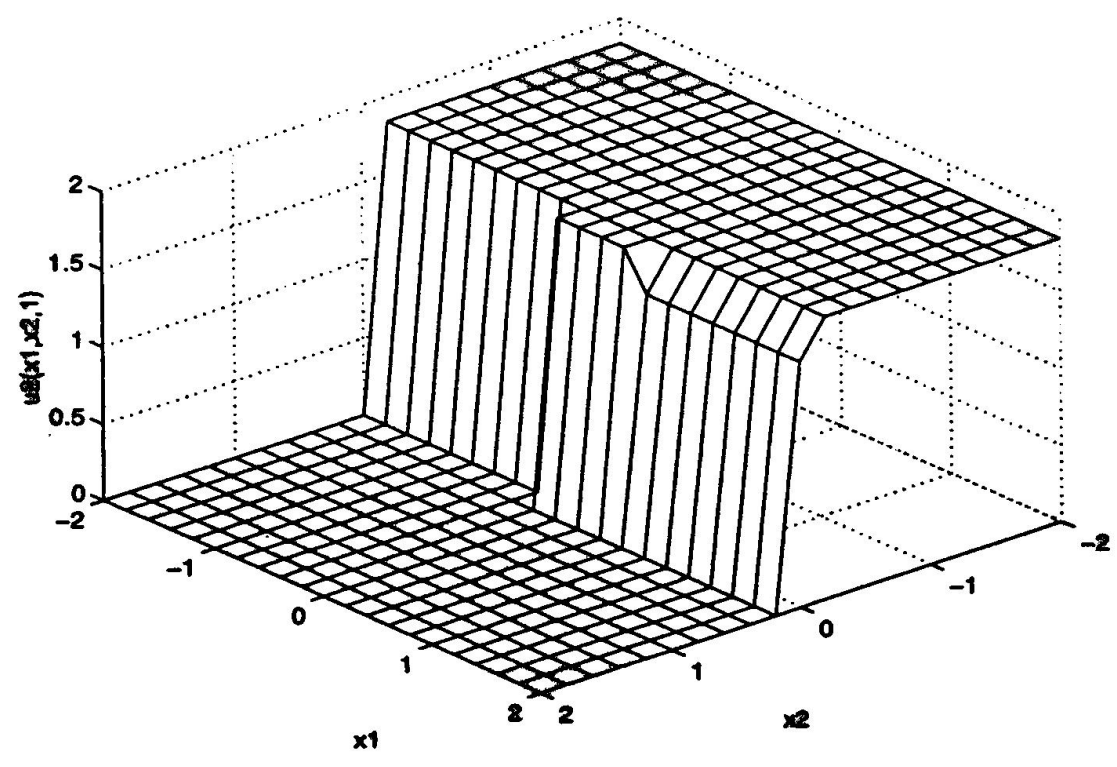

Figure 7: Production rate $\bar{u}_{2}\left(x_{1}, x_{2}, 1\right)$ for product 2

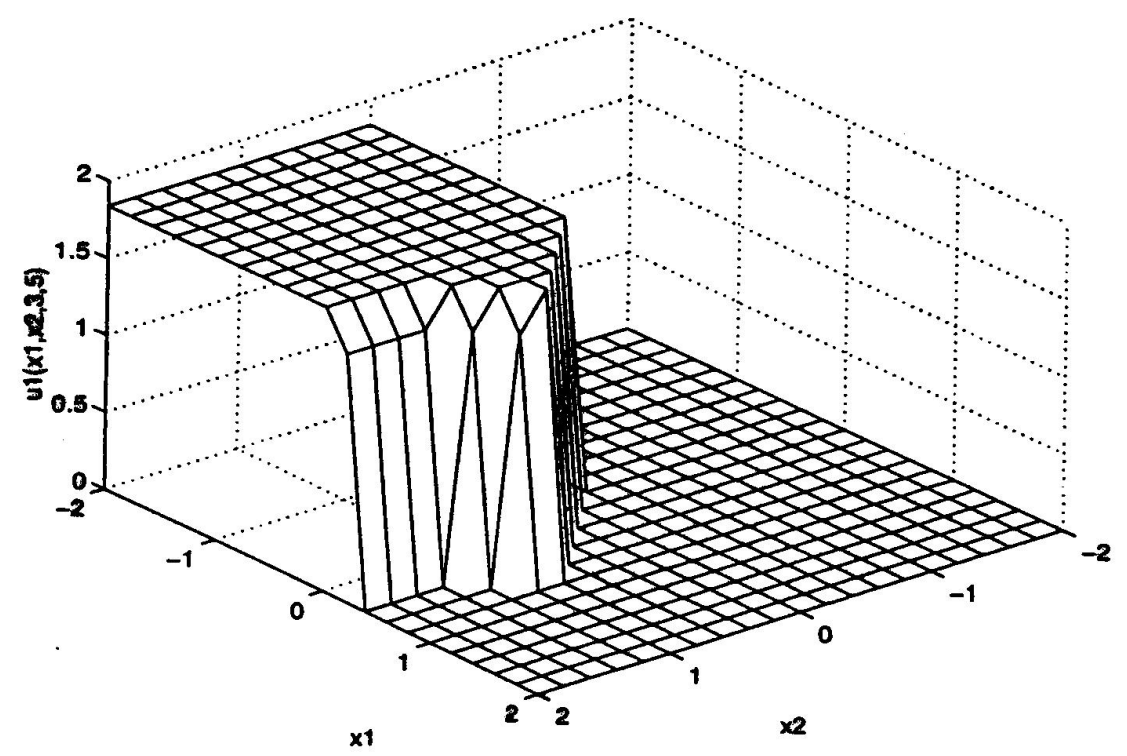

Figure 8: Production rate $\bar{u}_{1}\left(x_{1}, x_{2}, 5\right)$ for product 1 


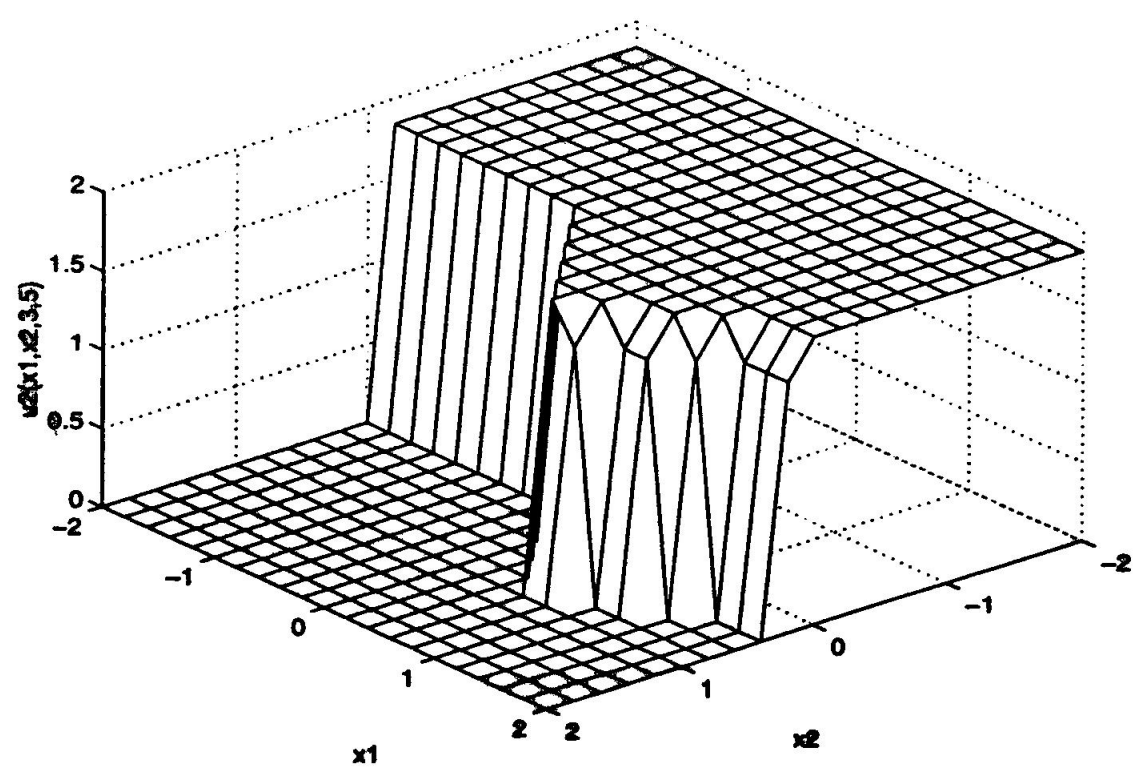

Figure 9: Production rate $\bar{u}_{2}\left(x_{1}, x_{2}, 5\right)$ for product 2

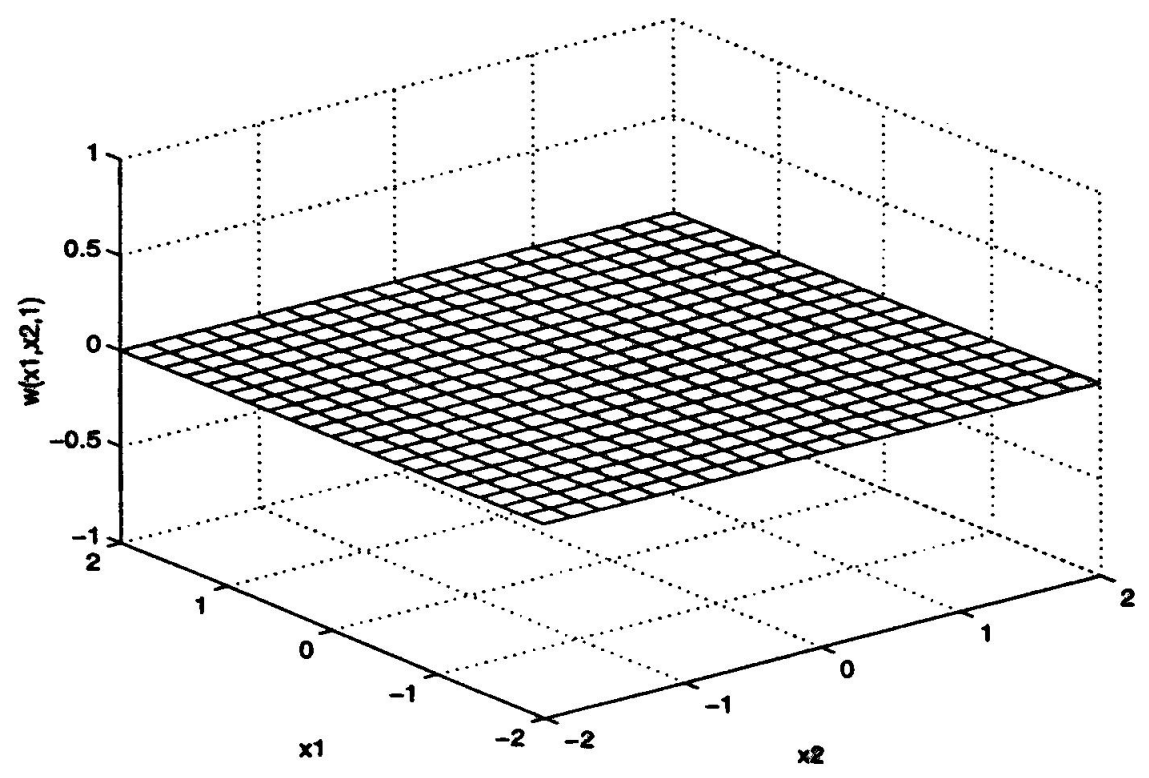

Figure 10: Preventive maintenance rate $\bar{\omega}\left(x_{1}, x_{2}, 1\right)$ for the limiting problem 


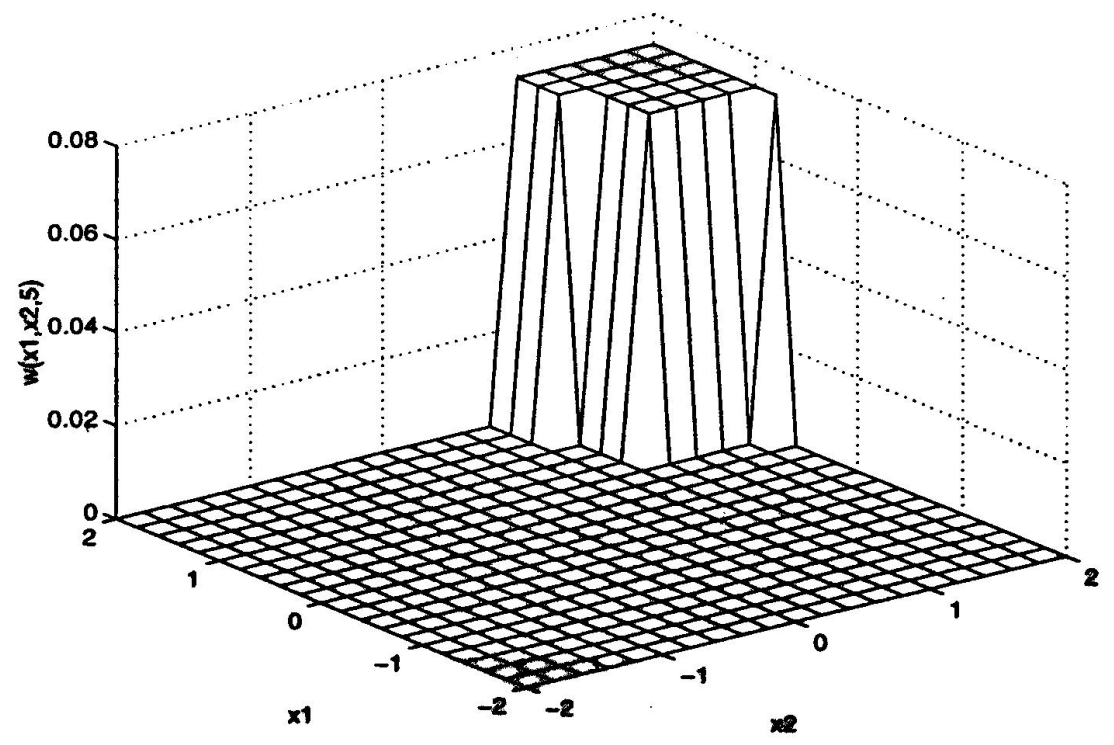

Figure 11: Preventive maintenance rate $\bar{\omega}\left(x_{1}, x_{2}, 5\right)$ for the limiting problem
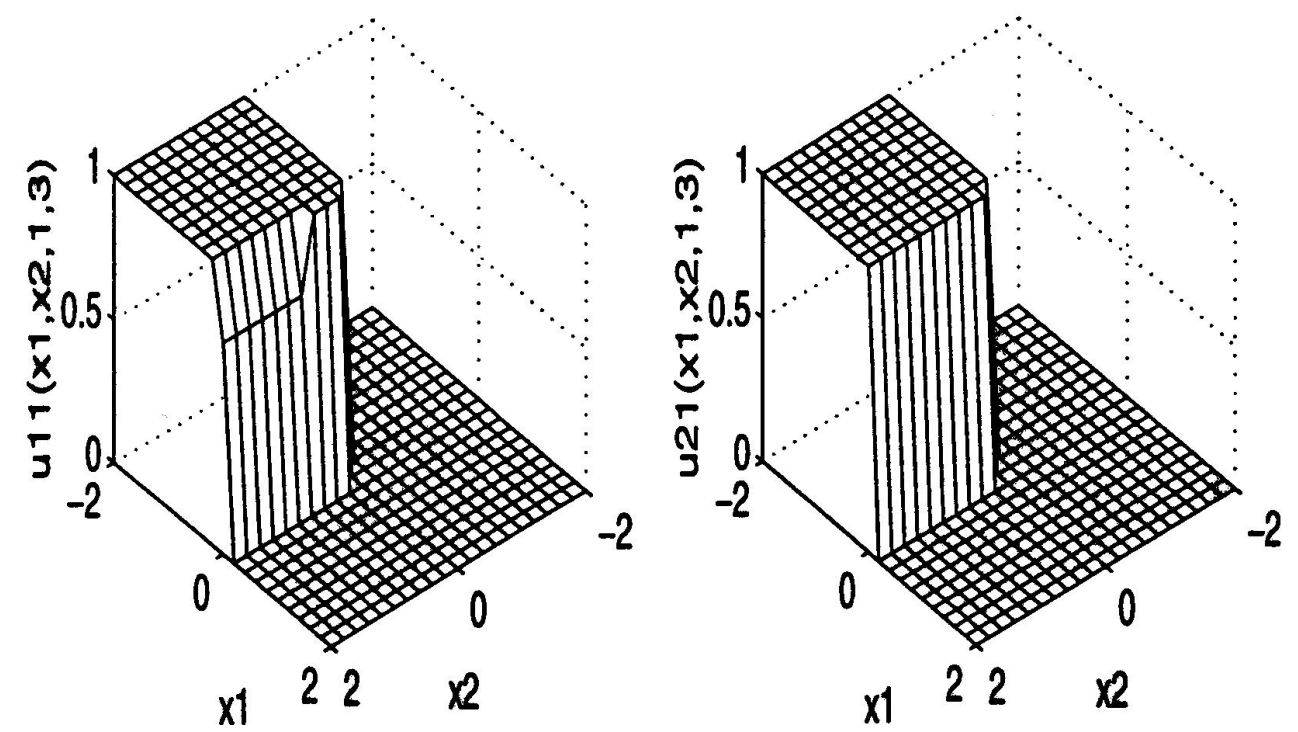

Figure 12: Machines production rates at mode 1 for $a_{1}=1$ and $a_{2}=3$ (product 1) 

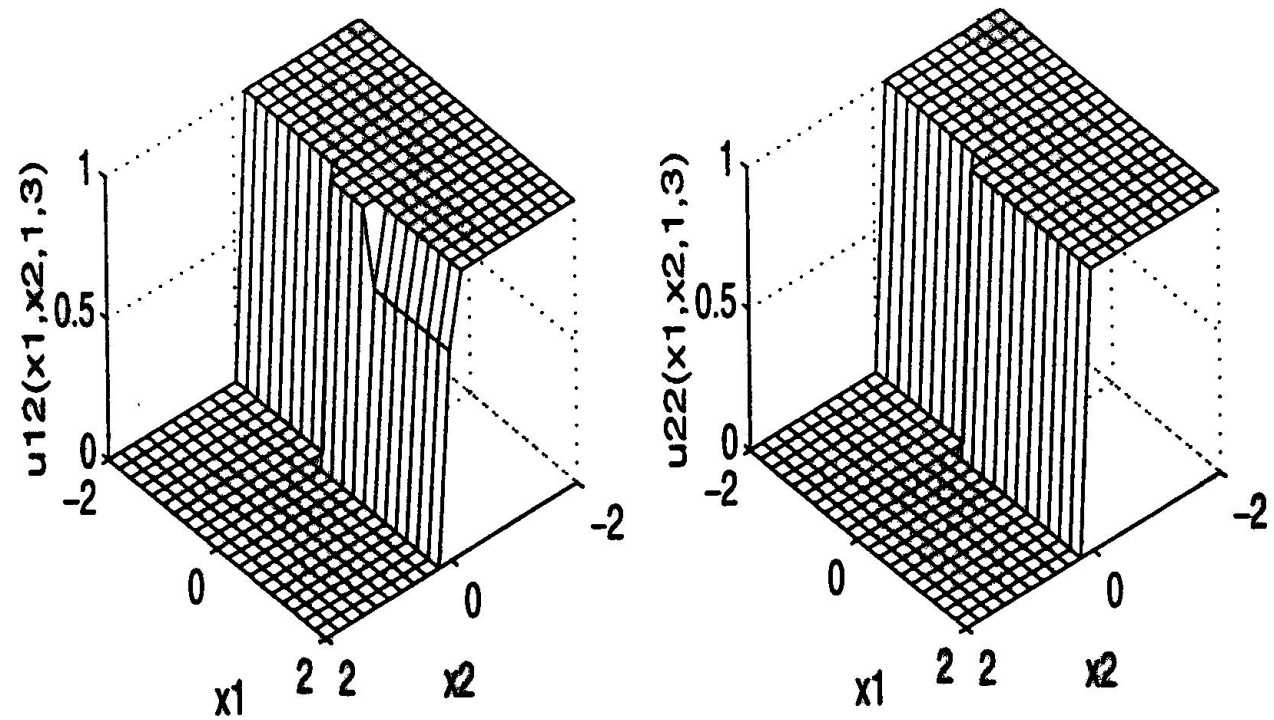

Figure 13: Machines production rates at mode 1 for $a_{1}=1$ and $a_{2}=3$ (product 2)
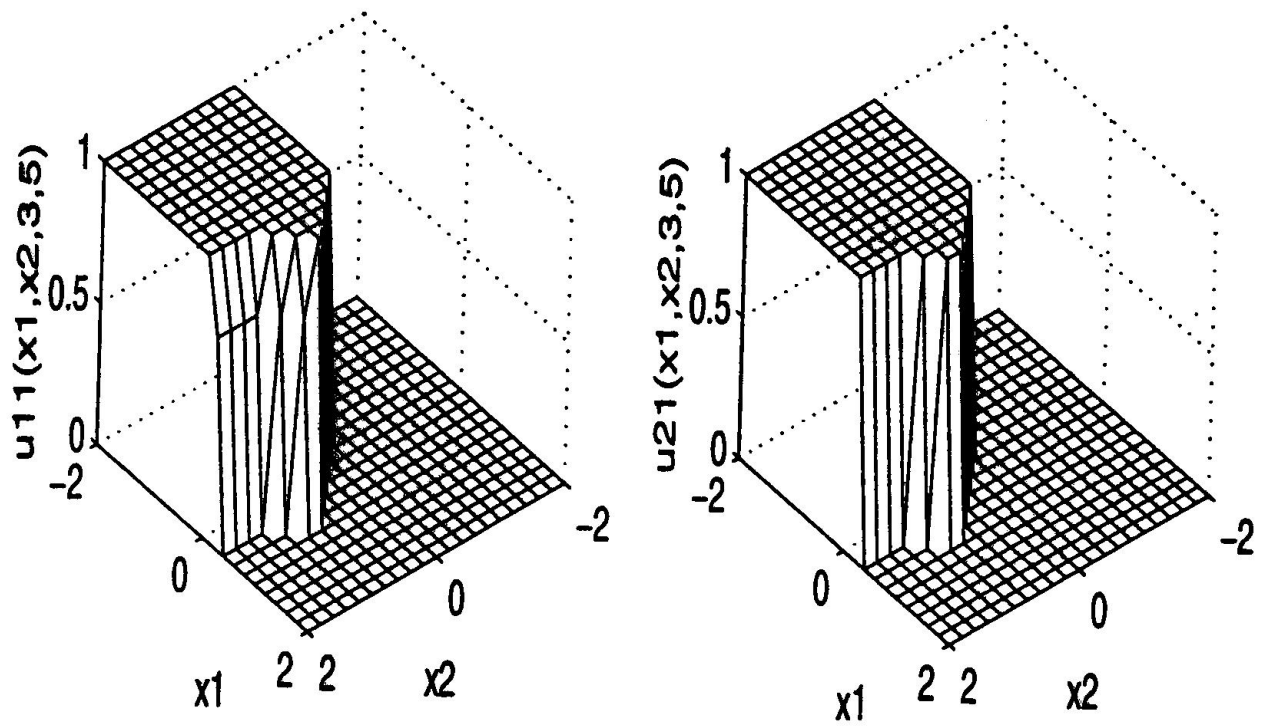

Figure 14: Machines production rates at mode 1 for $a_{1}=3$ and $a_{2}=5$ (product 1) 


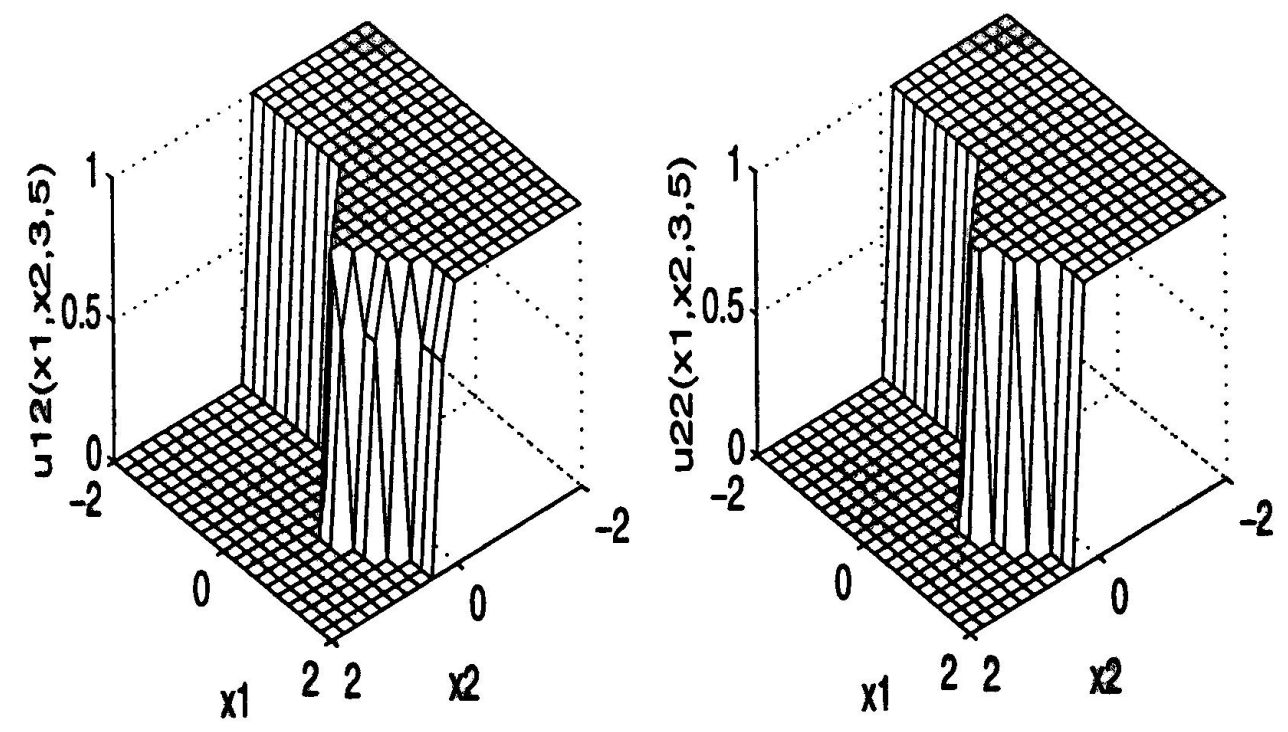

Figure 15: Machines production rates at mode 1 for $a_{1}=3$ and $a_{2}=5$ (product 2)
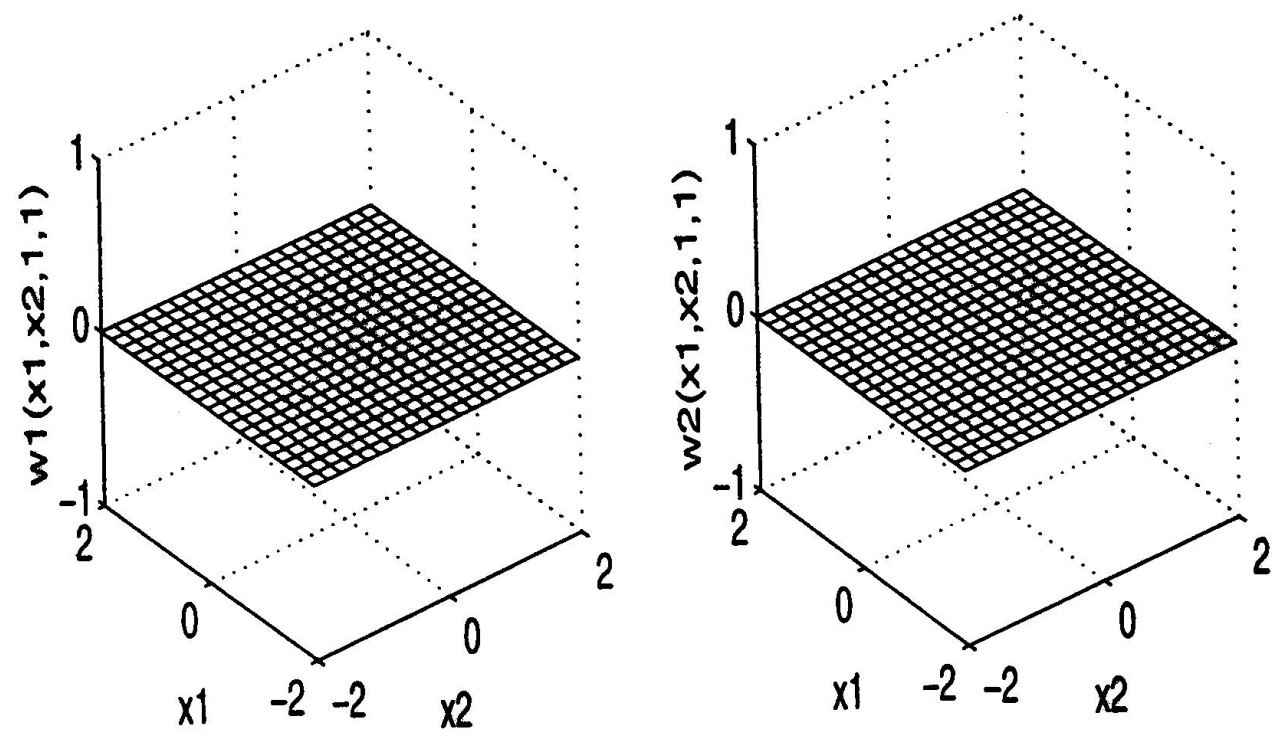

Figure 16: Machines preventive maintenance rates at mode 1 for $a_{1}=1$ et $a_{2}=3$ 

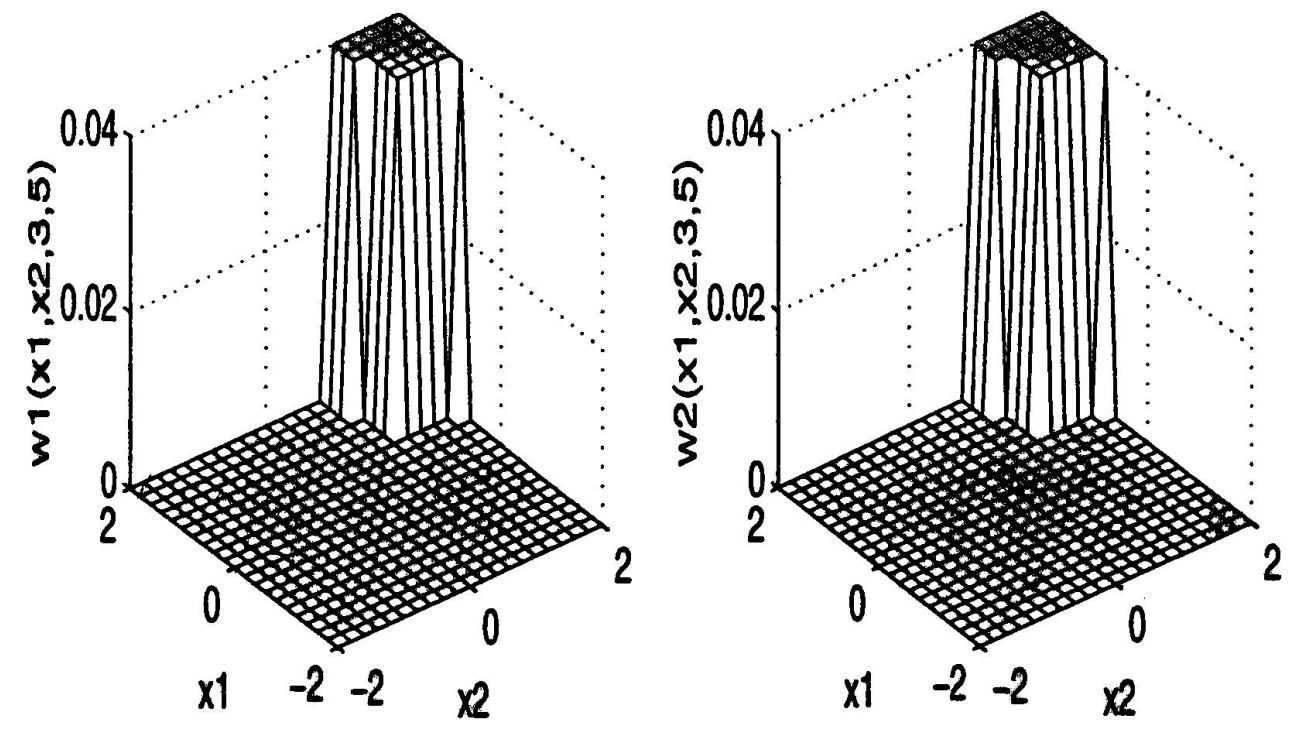

Figure 17: Machines preventive maintenance rates at mode 1 for $a_{1}=3$ et $a_{2}=5$ 


\section{CONCLUSION}

In this paper, we present the singular perturbation formulation of the production and preventive maintenance rates planning problem in manufacturing systems. We consider two times scale processes related to the rate at which the cost is discounted and the one at which machines failures occur. The obtained limiting problem has been shown to be more tractable numerically. This result can be very useful because of the large dimension of control problem in real world flexible manufacturing system. In such a system one can use the proposed approach to approximate the solution of the stochastic problem through the limiting problem concept. The quality of the results (their precision) achieved with the proposed heuristical method depends on the choice of the partition. A best approximation of the stochastic optimal control is ideally given by a partition with a large number of sets. But there is a practical limit with such a number. With a suitable number of partition sets, the proposed heuristical method, combined with the proposed hierarchical control approach extend the application of the singular perturbation method to non-homogeneous Markov processes (machine age and control dependent). The usefulness of the proposed approach is illustrated by the numerical example presented in this paper. 


\section{REFERENCES}

Akella, R., Kumar, P.R. (1986). Optimal Control of Production Rate in a Failure Prone Manufacturing System. IEEE Transactions on Automatic Control, 31(2), 116-126.

Boukas, E.K., Haurie, A. (1990). Manufacturing Flow Control and Preventive Maintenance : a Stochastic Control Approach. IEEE Transactions on Automatic Control, 35(9), 1024-1031.

Boukas, E.K., Kenne, J.P., Zhu, Q. (1995a). Age Dependent Hedging Point Policies in Manufacturing Systems. In Proc. of the American Control Conference, vol. 3 (pp. 2178-2179). Seattle, Washington.

Boukas, E.K., Zhang, Q., Yin, G. (1995b). Robust Production and Maintenance Planning in Stochastic Manufacturing Systems. IEEE Transactions on Automatic Control, 40(6), 1098-1102.

Clarke, F. (1983). Optimization and Non-Smooth Analysis. New York : WileyInterscience.

Gharbi, A., Kenne, J.P. (2000). Production and Preventive Maintenance Rates Control for a Manufacturing System : an Experimental Design Approach. International Journal of Production Economics, 65(3), 275-287.

Kenne, J.P. (1997). Planification de la production et de la maintenance des systèmes de production : approche hiérarchisée. Unpublished $\mathrm{PhD}$ Thesis, École Polytechnique, Montréal.

Kenne, J.P., Gharbi, A., Boukas, E.K. (1997). Control Policy Simulation Based on Machine Age in a Failure Prone One-Machine, One-Product Manufacturing System. International Journal of Production Research, 35(5), 1431-1445.

Kenne, J.P., Gharbi, A. (1999). Experimental Design in Production and Maintenance Control of a Single Machine, Single Product Manufacturing System. International Journal of Production Research, 37(3), 621-637.

Kenne, J.P., Gharbi, A. (2000). Production Planning Problem in Manufacturing Systems with General Failure and Repair Time Distributions. Production Planning and Control, 11(6), 581-588.

Kimemia, J.G., Gershwin, S.B. (1983). Algorithm for the Computer Control of a Flexible Manufacturing System. IIE Transactions, 15(4), 353-362. 
Lehoczky, J., Sethi, S., Soner, H.M., Taksar, M. (1991). An Asymptotic Analysis of Hierarchical Control of Manufacturing Systems Under Uncertainty. Mathematics of Operations Research, 16(3), 596-608.

Oldser, G.J., Suri, R. (1980). Time Optimal Control of Parts-Routing in a Manufacturing System with Failure Prone Machines. In Proc. $19^{\text {th }}$ IEEE Conference on Decision and Control (pp. 722-727). Albuquerque, New Mexico.

Pritsker, A.A.B., O'Reilly, J.J., LaVal, D.K. (1997). Simulation with Visual SLAM and AweSim. New York: J. Wiley and Sons.

Rishel, R. (1975). Dynamic Programming and Minimum Principles for Systems with Jump Markov Disturbances. SIAM Journal on Control, 13(2), 338-371.

Sethi, S.P., Zhang, Q. (1994a). Hierarchical Production Planning in Dynamic Stochastic Manufacturing Systems : Asymptotic Optimality and Error Bounds. Journal of Mathematical Analysis and Applications, 181(2), 285-319.

Sethi, S.P., Zhang, Q. (1994b). Hierarchical Control Decision Making in Stochastic Manufacturing Systems. Boston : Birkhauser.

Sethi, S.P., Suo, W., Taksar, M.I., Yan, H. (1998). Optimal Production Planning in a Multiple-Product Stochastic Manufacturing System with Long-Run Average Cost. Discrete Event Dynamic Systems : Theory and Applications, 8, 37-54.

Sharifnia, A. (1988). Production Control of Manufacturing System with Multiple Machine State. IEEE Transactions on Automatic Control, 33(7), 620-625.

Soner, H.M. (1993). Singular Perturbation in Manufacturing. SIAM Journal Control and Optimization, 31(1), 132-146. 